\title{
Phaeodactylum tricornutum photorespiration takes part in glycerol metabolism and is important for nitrogen-limited response
}

\author{
Aiyou Huang ${ }^{1}$, Lixia Liư ${ }^{2}$ Chen Yang ${ }^{2}$ and Guangce Wang ${ }^{1 *}$
}

\begin{abstract}
Background: Microalgae are potential sources of biofuels and high-value compounds. Mixotrophic conditions usually promote growth of microalgae. The pennate diatom Phaeodactylum tricornutum, with its short life cycle, completely sequenced genome, and ease of transformation, can be used as a model for studying carbon metabolism in microalgae.

Results: We compared the growth rate of $P$. tricornutum (IOCAS-001) under different conditions and labeled the cells using $\left[{ }^{13} \mathrm{C}\right]$ glycerol (GL). The results revealed GL promoted the growth of $P$. tricornutum. Ser and Gly were synthesized via photorespiration. The ${ }^{13} \mathrm{C}$ enrichment of Ser and Gly under nitrogen-limited conditions was much higher compared to other amino acids, indicating the enhancement of photorespiration. Addition of sodium acetate decreased the growth rate of $P$. tricornutum under nitrogen-limited conditions. Our results indicated that the $\mathrm{GL}$ carbon backbone enters the Calvin cycle in the form of dihydroxyacetone phosphate (DHAP), producing xylulose 5-phosphate (X5P) with a GL2_3-generated carbon backbone distributed at X5P1_2 and ribose 5-phosphate (R5P) with GL1-derived carbon atoms at R5P1 and R5P2. Both R5P and X5P can be converted into ribulose-1,5-bisphosphate (RuBP). By oxygenation of RuBP carboxylase/oxygenase (Rubisco) and metabolism through photorespiration, these RuBPs generate Ser and Gly with GL1 or GL2-derived carbon atoms at position 1 and GL1 or GL3-derived carbon atoms at other positions, resulting in a low level of ${ }^{13} \mathrm{C}$ enrichment of Gly1 and Ser1.
\end{abstract}

Conclusion: Our results indicated different strains of $P$. tricornutum have different mechanisms for organic carbon metabolism. Photorespiration is involved in GL metabolism and is important for the nitrogen-limited response in P. tricornutum.

Classification: Metabolic flux analysis, microalgae

Keywords: Phaeodactylum tricornutum, Photorespiration, Glycerol metabolism, Nitrogen-limited response

\section{Introduction}

Microalgae have received increasing attention as potential sources of biofuels, high-value chemicals, pharmaceuticals, bioactive compounds, and so on. Variations of culture conditions, including carbon source, have been investigated in attempts to promote the production of high-value compounds. Microalgae cultivated under mixotrophic conditions usually have higher growth rate and accumulate greater biomass as well as specific highvalue compounds at the plateau phase compared to

\footnotetext{
* Correspondence: gcwang@qdio.ac.cn

${ }^{1}$ Institute of Oceanology, Chinese Academy of Sciences, Qingdao 266071, China

Full list of author information is available at the end of the article
}

photoautotrophic conditions [1-3]. Acetate, for example, enhanced carotenoid biosynthesis in the late-exponential growth phase in Haematococcus pluvialis [4], and glucose, the common carbohydrate in bacterial culture, can be used by Chlorella and promotes the growth rate significantly [5]. A clear illustration of carbon metabolism, especially utilization of organic substrates and the mechanism underlying accumulation of high-value compounds, is important for industrialization of microalgae production. Related studies should be conducted, especially in model organisms.

Diatoms, which are believed to produce around onefifth of the primary productivity on earth [6,7], can produce approximately 46 tons of organic oil ha ${ }^{-1} \cdot \mathrm{year}^{-1}$

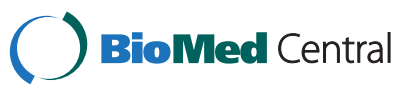


and are, therefore, potential sources of biodiesel fuel [8]. The pennate diatom Phaeodactylum tricornutum is an atypical diatom with a weakly silicified outer shell [9-12] that is ruptured easily by sonication or high-pressure homogenization, facilitating extraction of intracellular metabolites. P. tricornutum is a potential source of polyunsaturated fatty acids (PUFA) [13] and fucoxanthin [14], the marine carotenoid reported to exert anti-carcinogenic effects [15] as well as radical scavenging [16] and, most excitingly, to have anti-obesity properties $[17,18]$. The P. tricornutum (CCMP 2561) genome has been sequenced completely, providing a clear genetic background and revealing $P$. tricornutum adopts the metabolic pathways of both plants and animals [19]. P. tricornutum is easily transformed and can be regulated genetically [20-23]. Because of the characteristics mentioned above, $P$. tricornutum is considered to be a potential source for biodiesel and the production of high-value compounds, as well as a model for studying carbon metabolism in microalgae.

P. tricornutum is a photoautotrophic organism capable of photosynthesis using light energy and assimilating inorganic carbon sources, like plant cells. Also, there are reports of $P$. tricornutum using organic substrates as carbon and energy sources under mixotrophic conditions. The idea that $P$. tricornutum can use glycerol is quite widely known [1-3,24], whereas reports of its ability to use glucose were controversial $[25,26]$. To demonstrate a clear pathway for organic carbon metabolism in P. tricornutum, methods such as metabolic flux analysis can be used. Stationary metabolic flux analysis used ${ }^{13} \mathrm{C}$-labeled carbon source as substrate. During metabolism, the carbon backbone of the substrate is broken and recombined in different pathways, producing metabolites with different labeling patterns that can be detected through gas chromatography mass spectrometry (GC-MS) or nuclear magnetic resonance (NMR). These data can be used to calculate the contributions of different pathways to the synthesis of a defined metabolite, that is, flux ratios. Combined with a stoichiometric reaction model and extracellular consumption and secretion rates, these flux ratios can be used to quantify the net carbon fluxes in central carbon metabolism [27]. Based on ${ }^{13} \mathrm{C}$ labeling experiment using glucose and glycerol as carbon sources, Zheng et al. found unusual pathways were active in P. tricornutum (CCMP 632). Ser and Gly were largely synthesized via the glyoxylate (GOC) cycle followed by photorespiratory reactions [26]. This provided important information about glucose metabolism in P. tricornutum (CCMP 632). Nevertheless, some previous studies had reported that $P$. tricornutum cannot utilize glucose at all [25], indicting that different strains of $P$. tricornutum have different efficiencies of glucose metabolism. Strains that lack a glucose-utilizing ability might have a different mechanism for organic carbon metabolism from strains that can use glucose.
In this study, we compared the growth rates of $P$. tricornutum (IOCAS-001) under different conditions and labeled cells with $\left[{ }^{13} \mathrm{C}\right]$ glycerol (GL). The results revealed the strain in this study cannot use glucose. Ser and Gly were synthesized from GOC that origin from photorespiration but not the GOC cycle. Photorespiration was indeed involved in GL metabolism and was important for the nitrogen-limited response in $P$. tricornutum.

\section{Results}

\section{Growth of $P$. tricornutum under different culture} conditions

\section{Influence of carbon source}

We compared the growth rate of $P$. tricornutum (IOCAS-001) under conditions of no additional carbon source, 0.174 g. $\mathrm{L}^{-1} \mathrm{NaHCO}_{3}, 0.02 \mathrm{M}$ glucose, $0.02 \mathrm{M}$ $\mathrm{GL}$, and $0.02 \mathrm{M}$ glycine. The growth rate of $P$. tricornutum on $0.02 \mathrm{M}$ glucose or $0.02 \mathrm{M}$ glycine was significantly lower $(P<0.01)$ compared to $0.174 \mathrm{~g} \cdot \mathrm{L}^{-1} \mathrm{NaHCO}_{3}$ and even lower compared to that with no additional carbon source (Figure 1A,G). The growth rate of P. tricornutum with 0.02 M GL was higher $(P<0.05)$ compared to no additional carbon source and even higher $(P<0.05)$ than $0.174 \mathrm{~g} \cdot \mathrm{L}^{-1}$ $\mathrm{NaHCO}_{3}$ after 10 days of culturing (Figure 1A,G), indicating addition of GL promoted the growth of P. tricornutum, whereas glucose or glycine might not be utilized as carbon sources by $P$. tricornutum.

\section{Influence of GL concentration}

Because ${ }^{13} \mathrm{C}$-labeling GL is expensive, we optimized the concentration of GL to save substrate without affecting the growth rate of $P$. tricornutum. We compared the growth rate of $P$. tricornutum under conditions of no additional carbon source, $0.174 \mathrm{~g} \cdot \mathrm{L}^{-1} \mathrm{NaHCO}_{3}, 0.005 \mathrm{M}$, $0.02 \mathrm{M}$, and $0.1 \mathrm{M}$ GL. The results showed the growth rate of P. tricornutum on $0.005 \mathrm{M} \mathrm{GL}$ and with $0.174 \mathrm{~g} \cdot \mathrm{L}^{-1}$ $\mathrm{NaHCO}_{3}$ were similar, whereas the growth rate of $P$. tricornutum on $0.02 \mathrm{M}$ and $0.1 \mathrm{M}$ GL were similar and higher $(P<0.01)$ compared to $0.174 \mathrm{~g} \cdot \mathrm{L}^{-1} \mathrm{NaHCO}_{3}$ (Figure 1B,H), indicating $0.02 \mathrm{M} \mathrm{GL}$ was sufficient for the growth of P. tricornutum. We chose $0.02 \mathrm{M}$ GL as the substrate for mixotrophic growth of $P$. tricornutum.

\section{Influence of light}

Using $0.02 \mathrm{M}$ GL as the carbon source, we compared the growth rate of $P$. tricornutum under mixotrophic conditions (that is, GL assimilated simultaneously with $\mathrm{CO}_{2}$ fixation under cool white fluorescent lights with a $12 \mathrm{~h}$ dark/12 h light cycle) and heterotrophic conditions (no light during culture). The results showed P. tricornutum can used glycerol to sustain growth under heterotrophic conditions, though the growth rate was much lower $(P<0.01)$ compared to under mixotrophic conditions (Figure $1 \mathrm{C}, \mathrm{I}$ ), indicating light was important for 


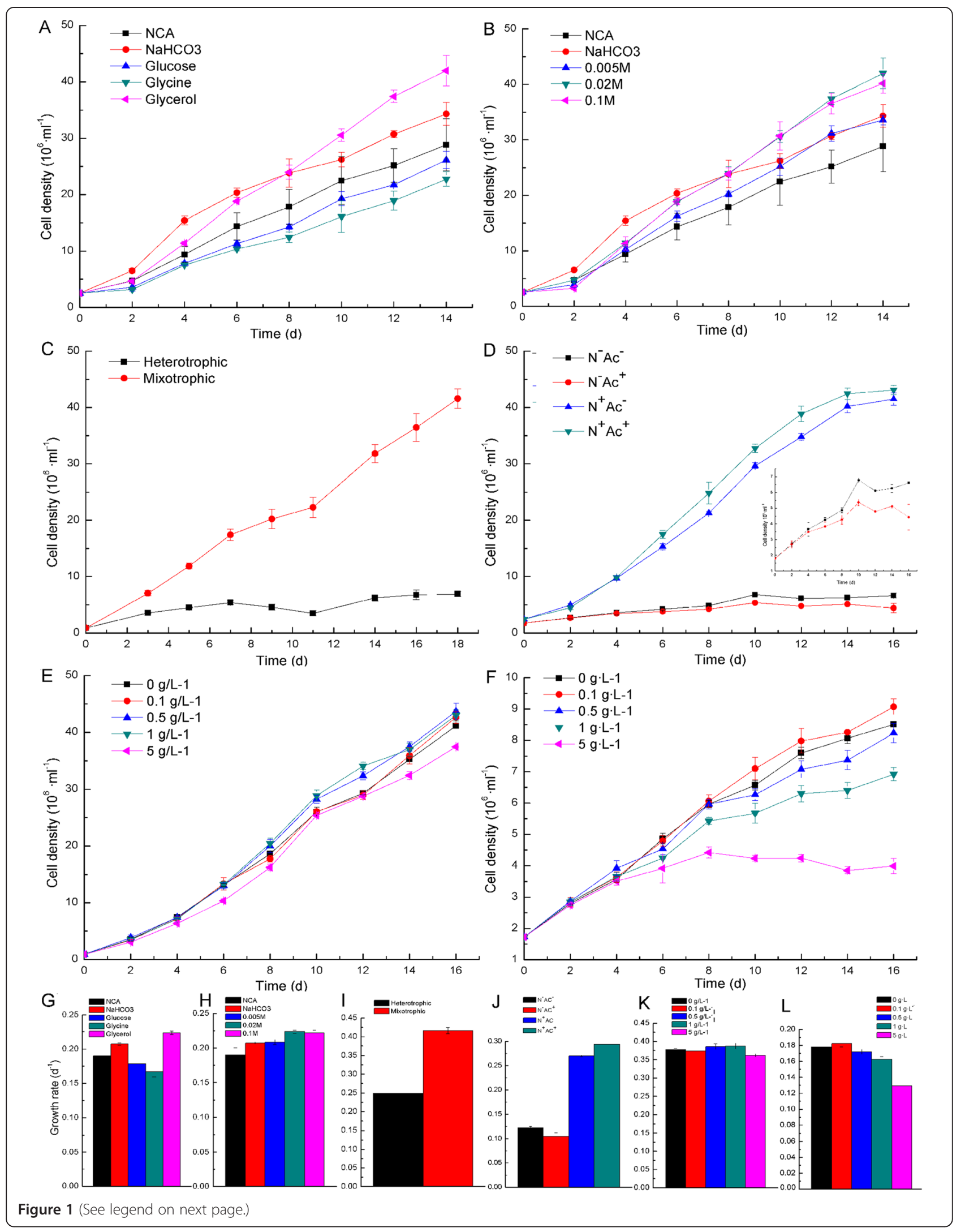


(See figure on previous page.)

Figure 1 Growth of $P$. tricornutum on different conditions. Cell densities and growth rates of $P$. tricornutum grown on different carbon sources (A, G), under different $G L$ concentrations $(\mathbf{B}, \mathbf{H})$, under mixotrophic and heterotrophic conditions $(\mathbf{C}, \mathbf{I})$ ), in the presence or absence of sodium acetate $\mathbf{( D ,} \mathbf{J})$, under different sodium acetate concentrations in the presence of nitrogen $(\mathbf{E}, \mathbf{K})$, and under different sodium acetate concentrations in the absence of nitrogen $(\mathbf{F}, \mathbf{L})$. A-F $Y$ axis, cell density $\left(10^{6} \cdot \mathrm{mL}^{-1}\right), X$ axis, culture time; G-L $Y$ axis, growth rate (day ${ }^{-1}$ ); NAC, no additional carbon source; $\mathrm{N}^{+} A c^{+}$, both sodium nitrate and sodium acetate plus; $\mathrm{N}^{+} A c^{-}$, sodium nitrate alone; $\mathrm{N}^{-} A c^{+}$, sodium acetate alone; $\mathrm{N}^{-} A c^{-}$, both sodium nitrate and sodium acetate minus. Error bars are the SD of three replicates.

growth of $P$. tricornutum even in the presence of GL as carbon source.

\section{Influence of sodium acetate}

To investigate the likely influence of sodium acetate on the growth rate of $P$. tricornutum, we compared the growth of $P$. tricornutum under different conditions (both sodium nitrate and sodium acetate plus, $\mathrm{N}^{+} \mathrm{Ac}^{+}$; sodium nitrate alone, $\mathrm{N}^{+} \mathrm{Ac}^{-}$; sodium acetate alone, $\mathrm{N}^{-} \mathrm{Ac}^{+}$; both sodium nitrate and sodium acetate minus, $\mathrm{N}^{-} \mathrm{Ac}^{-}$). The results indicted that in the presence of sodium nitrate, addition of sodium acetate can promote $(P<0.01)$ the growth of P. tricornutum (Figure 1D,J). While under sodium nitrate minus condition, addition of sodium acetate limited $(P<0.01)$ the growth of P. tricornutum (Figure 1D,J).

To further investigate the dose-response effect of acetate on growth rate of $P$. tricornutum, sodium acetate was added to different concentrations $\left(0,0.1,0.5,1\right.$, and $\left.5 \mathrm{~g} \cdot \mathrm{L}^{-1}\right)$ under sodium nitrate plus or minus conditions. The results indicted that, compared to acetate minus conditions, 0.1 g. $\mathrm{L}^{-1}$ sodium acetate had a negligible influence on growth of $P$. tricornutum under both sodium nitrate plus and minus conditions, 0.5 and $1 \mathrm{~g} \cdot \mathrm{L}^{-1}$ sodium acetate had a positive influence $(P<0.05)$ under nitrate plus conditions and a negative effect $(P<0.05)$ under nitrate minus conditions, while $5 \mathrm{~g} \cdot \mathrm{L}^{-1}$ sodium acetate limited $(P<0.01)$ the growth of $P$. tricornutum under both nitrate plus and minus conditions (Figure 1E,F,K,L).

\section{Change in glycerol and acetate concentration}

To verify the consumption of glycerol and acetate, the supernatants from cultures under $\mathrm{N}^{+} \mathrm{Ac}^{+}, \mathrm{N}^{+} \mathrm{Ac}^{-}, \mathrm{N}^{-} \mathrm{Ac}^{+}$, and $\mathrm{N}^{-} \mathrm{Ac}^{-}$conditions were collected, and glycerol and acetate concentrations were determined. There was a significant decrease in glycerol concentration under $\mathrm{N}^{+} \mathrm{Ac}^{+}$and $\mathrm{N}^{+} \mathrm{Ac}^{-}$conditions (from approximately 2000 to approximately $1600 \mathrm{mg} \cdot \mathrm{L}^{-1}$, Figure $\left.2 \mathrm{~A}, \mathrm{~B}\right)$, while the consumption of glycerol under $\mathrm{N}^{-} \mathrm{Ac}^{+}$and $\mathrm{N}^{-} \mathrm{Ac}^{-}$conditions was not significant (Figure 2C,D). Similarly, the consumption of acetate was significant under $\mathrm{N}^{+} \mathrm{Ac}^{+}$conditions (from approximately 960 to approximately $870 \mathrm{mg} \cdot \mathrm{L}^{-1}$ sodium acetate, Figure $2 \mathrm{E}$ ) but not obvious under $\mathrm{N}^{-} \mathrm{Ac}^{+}$conditions (Figure 2F). It was likely that the decrease in glycerol and acetate concentrations under $\mathrm{N}^{-}$condition was too slight to be detected. As the biomass did not increase much under
$\mathrm{N}^{-}$condition, possibly only a little glycerol and acetate were consumed.

\section{Total lipid content}

Total lipid content was determined to verify if consumption of acetate influenced synthesis of total lipid. Though acetate was consumed under $\mathrm{N}^{+} \mathrm{Ac}^{+}$conditions, there was no significant difference between total lipid contents of $\mathrm{N}^{+} \mathrm{Ac}^{+}$and $\mathrm{N}^{+} \mathrm{Ac}^{-}$(Figure 3). There was no significant difference between total lipid contents of $\mathrm{N}^{-} \mathrm{Ac}^{+}$ and $\mathrm{N}^{-} \mathrm{Ac}^{-}$, either (Figure 3). Total lipid contents range from approximately $38 \%$ to approximately $46 \%$ cell dry weight (CDW).

\section{${ }^{13} \mathrm{C}$-labeling experiment \\ Acclimation of P. tricornutum to an organic carbon source under mixotrophic conditions}

To investigate the metabolism of GL in P. tricornutum, we cultured $P$. tricornutum using $\left[{ }^{13} \mathrm{C}\right] \mathrm{GL}$ and detected the distribution of ${ }^{13} \mathrm{C}$ enrichments in amino acids. At first, the cultures used as inocula were grown on $f / 2$ medium with $\mathrm{NaHCO}_{3}$ as carbon source, and the level of $\left[\mathrm{U}_{-}{ }^{13} \mathrm{C}\right] \mathrm{GL}$ was $20 \%$. Table 1 gives the corrected abundance of the mass isotopomers for hydrolyzed amino acids in $20 \%$ [U- ${ }^{13} \mathrm{C}$ ] GL labeling experiments; the mean fractional labeling (FL) was approximately 0.047. As the ${ }^{13} \mathrm{C}$ isotope is stable and the natural abundance is 0.011 [28], the experimental error of some fragments, which were slightly higher than the natural ${ }^{13} \mathrm{C}$ abundance, might be large. Thus, these data were not analyzed further. We suggested the reason might be because the cultures used as inocula were cultivated with $\mathrm{NaHCO}_{3}$ as carbon source, and the cell might need time for acclimation before it can utilize GL when transferred to medium with GL as carbon source.

Next, cultures used for inocula were acclimated to organic carbon source for approximately 3 months by repeated transfer of cells in the mid-exponential growth phase into fresh medium with GL as carbon source, and the level of $\left[\mathrm{U}_{-}{ }^{13} \mathrm{C}\right] \mathrm{GL}$ was increased to $30 \%$. Table 1 gives the FL for hydrolyzed amino acids in $30 \%$ $\left[\mathrm{U}_{-}{ }^{13} \mathrm{C}\right] \mathrm{GL}$ labeling experiments; the mean FL was approximately 0.150 . Fragments from Phe and Tyr, which are generally synthesized from phosphoenolpyruvate (PEP) and erythrose-4-P (E4P), had similar values of mass 


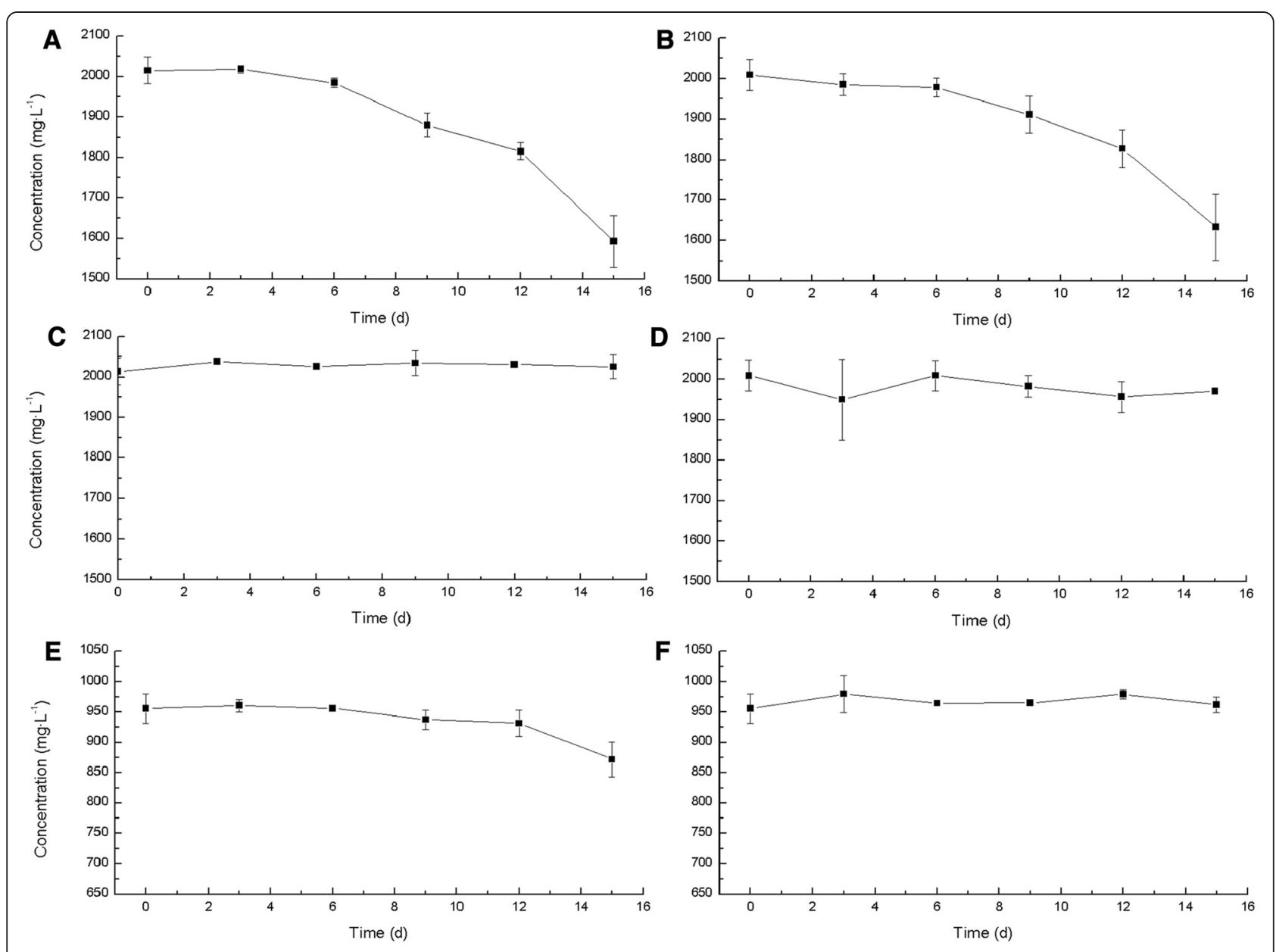

Figure 2 Change in glycerol and acetate concentrations under different conditions. Change of glycerol concentration under $\mathrm{N}^{+} A C^{+}(\mathbf{A}), \mathrm{N}^{+} A c^{-}(\mathbf{B}), \mathrm{N}^{-} A C^{+}$ (C), and $\mathrm{N}^{-} \mathrm{Ac}^{-}$(D) conditions and change of sodium acetate concentration under $\mathrm{N}^{+} \mathrm{Ac}^{+}(\mathbf{E})$ and $\mathrm{N}^{-} \mathrm{Ac}^{+} \mathbf{( F )}$ conditions.

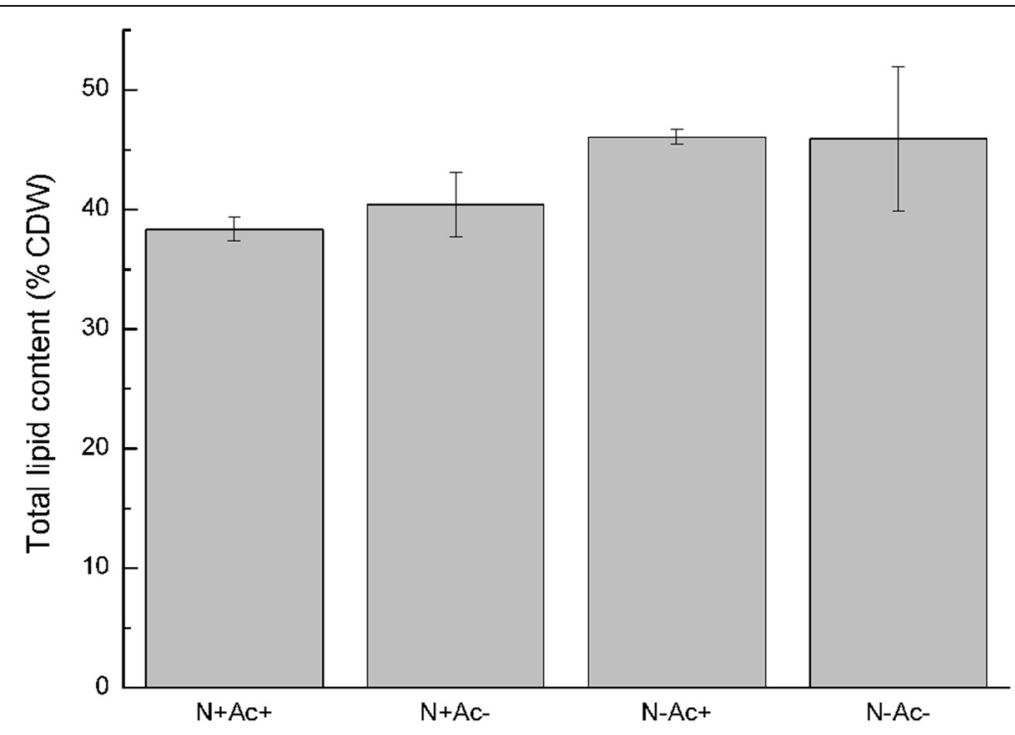

Figure 3 Total lipid contents under $\mathrm{N}^{+} A C^{+}, \mathrm{N}^{+} A C^{-}, \mathrm{N}^{-} A C^{+}$, and $\mathrm{N}^{-} A C^{-}$conditions. 
Table 1 FLs for amino acids under different labeling experiments

\begin{tabular}{|c|c|c|c|c|c|}
\hline Fragments & $20 \% \mathrm{U}^{13} \mathrm{C}^{\mathrm{a}}$ & $30 \% \mathrm{U}-{ }^{13} \mathrm{C} \mathrm{N}+{ }^{\mathrm{b}}$ & $30 \% \mathrm{U}-^{13} \mathrm{C} \mathrm{N}^{-\mathrm{C}}$ & $1,3-{ }^{13} C N+{ }^{d}$ & $1,3-^{13} \mathrm{CN}^{-}{ }^{e}$ \\
\hline M_ala_057 & $0.057 \pm 0.003$ & $0.180 \pm 0.015$ & $0.122 \pm 0.006$ & $0.190 \pm 0.012$ & $0.161 \pm 0.005$ \\
\hline M_ala_085 & $0.076 \pm 0.001$ & $0.195 \pm 0.013$ & $0.143 \pm 0.005$ & $0.202 \pm 0.009$ & $0.180 \pm 0.004$ \\
\hline M_asx_057 & $0.041 \pm 0.001$ & $0.146 \pm 0.011$ & $0.094 \pm 0.003$ & $0.151 \pm 0.016$ & $0.119 \pm 0.003$ \\
\hline M_asx_085 & $0.045 \pm 0.001$ & $0.149 \pm 0.012$ & $0.097 \pm 0.003$ & $0.159 \pm 0.016$ & $0.125 \pm 0.004$ \\
\hline M_asx_302 & $0.042 \pm 0.001$ & $0.149 \pm 0.010$ & $0.097 \pm 0.003$ & $0.148 \pm 0.016$ & $0.115 \pm 0.004$ \\
\hline M_glx_057 & $0.046 \pm 0.001$ & $0.168 \pm 0.015$ & $0.140 \pm 0.001$ & $0.175 \pm 0.013$ & $0.155 \pm 0.005$ \\
\hline M_glx_085 & $0.047 \pm 0.002$ & $0.170 \pm 0.017$ & $0.144 \pm 0.004$ & $0.183 \pm 0.013$ & $0.165 \pm 0.003$ \\
\hline M_glx_302 & $0.068 \pm 0.004$ & $0.170 \pm 0.014$ & $0.154 \pm 0.022$ & $0.157 \pm 0.007$ & $0.157 \pm 0.015$ \\
\hline M_gly_057 & $0.049 \pm 0.002$ & $0.172 \pm 0.013$ & $0.294 \pm 0.025$ & $0.190 \pm 0.008$ & $0.219 \pm 0.002$ \\
\hline M_gly_085 & $0.050 \pm 0.003$ & $0.173 \pm 0.014$ & $0.292 \pm 0.025$ & $0.254 \pm 0.006$ & $0.362 \pm 0.004$ \\
\hline M_his_057 & - & $0.127 \pm 0.006$ & - & $0.107 \pm 0.029$ & $0.103 \pm 0.036$ \\
\hline M_his_159 & - & $0.144 \pm 0.026$ & - & $0.127 \pm 0.013$ & $0.109 \pm 0.008$ \\
\hline M_his_302 & - & $0.134 \pm 0.010$ & - & $0.121 \pm 0.015$ & $0.096 \pm 0.021$ \\
\hline M_ile_015 & $0.041 \pm 0.001$ & $0.128 \pm 0.006$ & $0.047 \pm 0.026$ & $0.124 \pm 0.012$ & $0.072 \pm 0.043$ \\
\hline M_ile_085 & $0.048 \pm 0.002$ & $0.133 \pm 0.005$ & $0.069 \pm 0.001$ & $0.137 \pm 0.014$ & $0.109 \pm 0.001$ \\
\hline M_leu_015 & $0.041 \pm 0.001$ & $0.135 \pm 0.005$ & $0.060 \pm 0.013$ & $0.136 \pm 0.013$ & $0.109 \pm 0.004$ \\
\hline M_leu_085 & $0.047 \pm 0.002$ & $0.141 \pm 0.005$ & $0.069 \pm 0.003$ & $0.150 \pm 0.014$ & $0.120 \pm 0.002$ \\
\hline M_lys_057 & $0.042 \pm 0.002$ & $0.117 \pm 0.006$ & $0.073 \pm 0.024$ & $0.117 \pm 0.012$ & $0.090 \pm 0.000$ \\
\hline M_lys_159 & $0.051 \pm 0.004$ & $0.119 \pm 0.006$ & $0.089 \pm 0.046$ & $0.121 \pm 0.016$ & $0.095 \pm 0.001$ \\
\hline M_lys_302 & $0.064 \pm 0.010$ & $0.129 \pm 0.005$ & $0.078 \pm 0.072$ & $0.092 \pm 0.009$ & $0.087 \pm 0.002$ \\
\hline M_met_057 & $0.000 \pm 0.000$ & $0.148 \pm 0.011$ & $0.106 \pm 0.031$ & $0.163 \pm 0.014$ & $0.161 \pm 0.003$ \\
\hline M_met_085 & $0.000 \pm 0.000$ & $0.150 \pm 0.011$ & $0.142 \pm 0.009$ & $0.180 \pm 0.017$ & $0.179 \pm 0.010$ \\
\hline M_phe_057 & $0.050 \pm 0.001$ & $0.142 \pm 0.006$ & $0.069 \pm 0.006$ & $0.140 \pm 0.013$ & $0.118 \pm 0.026$ \\
\hline M_phe_085 & $0.048 \pm 0.002$ & $0.143 \pm 0.006$ & $0.073 \pm 0.015$ & $0.139 \pm 0.014$ & $0.101 \pm 0.013$ \\
\hline M_phe_302 & $0.045 \pm 0.003$ & $0.137 \pm 0.009$ & $0.056 \pm 0.003$ & $0.111 \pm 0.012$ & $0.073 \pm 0.004$ \\
\hline M_phe_sc & $0.098 \pm 0.002$ & $0.196 \pm 0.008$ & $0.366 \pm 0.165$ & $0.198 \pm 0.014$ & $0.339 \pm 0.191$ \\
\hline M_pro_057 & $0.044 \pm 0.001$ & $0.140 \pm 0.011$ & $0.119 \pm 0.018$ & $0.158 \pm 0.017$ & $0.121 \pm 0.008$ \\
\hline M_pro_085 & $0.042 \pm 0.001$ & $0.148 \pm 0.012$ & $0.106 \pm 0.005$ & $0.162 \pm 0.020$ & $0.119 \pm 0.001$ \\
\hline M_ser_057 & $0.057 \pm 0.001$ & $0.183 \pm 0.012$ & $0.313 \pm 0.011$ & $0.225 \pm 0.009$ & $0.257 \pm 0.001$ \\
\hline M_ser_085 & $0.058 \pm 0.001$ & $0.184 \pm 0.012$ & $0.303 \pm 0.014$ & $0.269 \pm 0.008$ & $0.346 \pm 0.005$ \\
\hline M_ser_302 & $0.057 \pm 0.001$ & $0.185 \pm 0.012$ & $0.323 \pm 0.018$ & $0.199 \pm 0.008$ & $0.211 \pm 0.001$ \\
\hline M_thr_057 & $0.041 \pm 0.001$ & $0.124 \pm 0.008$ & $0.070 \pm 0.002$ & $0.128 \pm 0.017$ & $0.095 \pm 0.001$ \\
\hline M_thr_085 & $0.040 \pm 0.005$ & $0.125 \pm 0.008$ & $0.077 \pm 0.006$ & $0.132 \pm 0.014$ & $0.100 \pm 0.001$ \\
\hline M_thr_sC & $0.117 \pm 0.003$ & $0.180 \pm 0.008$ & $0.155 \pm 0.030$ & $0.188 \pm 0.014$ & $0.167 \pm 0.014$ \\
\hline M_val_057 & $0.047 \pm 0.002$ & $0.145 \pm 0.006$ & $0.073 \pm 0.004$ & $0.150 \pm 0.013$ & $0.109 \pm 0.003$ \\
\hline M_val_085 & $0.054 \pm 0.002$ & $0.152 \pm 0.005$ & $0.087 \pm 0.007$ & $0.152 \pm 0.013$ & $0.118 \pm 0.002$ \\
\hline M_val_302 & $0.049 \pm 0.001$ & $0.152 \pm 0.005$ & $0.080 \pm 0.005$ & $0.138 \pm 0.013$ & $0.101 \pm 0.004$ \\
\hline M_tyr_057 & $0.048 \pm 0.002$ & $0.140 \pm 0.005$ & $0.063 \pm 0.005$ & $0.140 \pm 0.013$ & $0.103 \pm 0.019$ \\
\hline M_tyr_085 & $0.053 \pm 0.001$ & $0.143 \pm 0.005$ & $0.096 \pm 0.041$ & $0.140 \pm 0.013$ & $0.150 \pm 0.098$ \\
\hline M_tyr_302 & $0.047 \pm 0.003$ & $0.140 \pm 0.010$ & $0.064 \pm 0.005$ & $0.112 \pm 0.011$ & $0.078 \pm 0.006$ \\
\hline average FL & $0.047 \pm 0.005$ & $0.150 \pm 0.008$ & $0.121 \pm 0.005$ & $0.157 \pm 0.014$ & $0.141 \pm 0.007$ \\
\hline
\end{tabular}

${ }^{\mathrm{a}} \mathrm{FLs}$ for amino acids under $20 \%\left[\mathrm{U}-{ }^{13} \mathrm{C}\right.$ ]glycerol labeling experiments, cultures with $\mathrm{NaHCO}_{3}$ as carbon source was used as inocula; ${ }^{\mathrm{b}} \mathrm{FLs}$ for amino acids under $30 \%$ $\left[\mathrm{U}-{ }^{13} \mathrm{C}\right]$ glycerol labeling experiments, nitrogen plus; ${ }^{\mathrm{C}} \mathrm{FL}$ for amino acids under $30 \%\left[\mathrm{U}-{ }^{13} \mathrm{C}\right]$ glycerol labeling experiments, nitrogen minus; ${ }^{\mathrm{d}} \mathrm{FLs}$ for amino acids under $50 \%\left[1,3-{ }^{13} \mathrm{C}\right]$ glycerol labeling experiments, nitrogen plus; ${ }^{\mathrm{e}} \mathrm{FLs}$ for amino acids under $50 \%\left[1,3-{ }^{13} \mathrm{C}\right]$ glycerol labeling experiments, nitrogen minus. 
distribution vector (MDV) (M_Phe_057, M_Phe_085, and M_Phe_302 versus M_Tyr_057, M_Tyr_085, and M_Tyr 302), confirming the consistency of GC-MS results.

\section{The FL values of amino acids synthesized in different cell partitions were diluted to different degrees}

Under mixotrophic conditions, different amino acid fragments had different FL values (Table 1) regardless of the type of labeling substrates $\left(\left[\mathrm{U}_{-}{ }^{13} \mathrm{C}\right] \mathrm{GL}\right.$ or $\left.\left[1,3-{ }^{13} \mathrm{C}\right] \mathrm{GL}\right)$. Eight amino acids (Lys, Thr, Ile, Leu, Tyr, His, Phe, and Val), which were reported to be synthesized in chloroplasts in higher plants, mainly had mostly lower average FL values, whereas average $F L$ values for Ala, Ser, Gly, and Glx were higher (Table 2). This indicated GL was assimilated simultaneously with $\mathrm{CO}_{2}$ fixation in chloroplasts, resulting in different dilutions of FL values between amino acids synthesized in different cell partitions.

\section{${ }^{13} \mathrm{C}$ enrichment of Ser and Gly in the absence of nitrogen} As shown in Table 1, under nitrogen plus conditions, Ala had the highest average FL value followed by Ser, Gly, and Glx. In the absence of nitrogen, FL values of Ser and Gly were increased significantly with levels close to the ${ }^{13} \mathrm{C}$ enrichment of substrate, indicating the Ser and Gly metabolic pathway was important for the nitrogen-limitation response in $P$. tricornutum.

\section{Positional labeling of Ser and Gly based on $\left[\mathrm{U}^{13}{ }^{13} \mathrm{C}\right] \mathrm{GL}$ or $\left[1,3-{ }^{13} \mathrm{C}\right] \mathrm{GL}$}

We calculated the positional labeling of Ser and Gly to investigate the likely pathway for Ser and Gly metabolism in

Table 2 Average FL values for hydrolyzed amino acids in nitrogen plus $\left(\mathrm{U}^{13} \mathrm{C}\right)$ labeling experiment

\begin{tabular}{ll}
\hline AA & FL \pm SD \\
\hline Lys & $0.118 \pm 0.006$ \\
Thr & $0.124 \pm 0.008$ \\
Ile & $0.130 \pm 0.005$ \\
Leu & $0.138 \pm 0.005$ \\
Tyr & $0.141 \pm 0.006$ \\
His & $0.135 \pm 0.015$ \\
Phe & $0.140 \pm 0.007$ \\
Val & $0.149 \pm 0.005$ \\
Asx & $0.148 \pm 0.011$ \\
Met & $0.149 \pm 0.011$ \\
Pro & $0.148 \pm 0.012$ \\
Gly & $0.172 \pm 0.014$ \\
Glx & $0.169 \pm 0.015$ \\
Ser & $0.184 \pm 0.012$ \\
Ala & $0.188 \pm 0.014$ \\
\hline FL fractional labeling: SD, standard deviation
\end{tabular}

$\mathrm{FL}$, fractional labeling; SD, standard deviation.
P. tricornutum. When $\left[\mathrm{U}_{-}{ }^{13} \mathrm{C}\right] \mathrm{GL}$ was used as substrate, both Ser and Gly had similar ${ }^{13} \mathrm{C}$ enrichment in all positions, regardless of the nitrogen conditions (Table 3). When $\left[1,3-{ }^{13} \mathrm{C}\right] \mathrm{GL}$ was used as substrate in the presence of nitrogen, the ${ }^{13} \mathrm{C}$ enrichment of Ser1 was significantly lower (approximately half) compared to Ser2 and Ser3, and the ${ }^{13} \mathrm{C}$ enrichment of Gly1 was also approximately half compared to Gly2 (Table 3). Moreover, the ${ }^{13} \mathrm{C}$ enrichment of Ser1 and Gly1 was decreased significantly in the absence of nitrogen, suggesting the majority of Ser1 and Gly1 were derived from GL2, consistent with the report of Zheng et al. [26].

\section{Change in intracellular metabolite pools in response to nitrate limitation and acetate addition}

Table 4 shows the ratios of abundances of key cellular metabolites under different culture conditions $\left(\mathrm{N}^{-} \mathrm{Ac}^{+}\right.$, $\mathrm{N}^{-} \mathrm{Ac}^{-}, \mathrm{N}^{+} \mathrm{Ac}^{+}$, and $\mathrm{N}^{+} \mathrm{Ac}^{-}$). Gly, ethylene glycol, and formate increased under $\mathrm{N}^{-}$conditions $\left(\mathrm{N}^{-} \mathrm{Ac}^{+} / \mathrm{N}^{+} \mathrm{Ac}^{+}\right.$ and $\mathrm{N}^{-} \mathrm{Ac}^{-} / \mathrm{N}^{+} \mathrm{Ac}^{-}$) and were reduced when acetate was added $\left(\mathrm{N}^{-} \mathrm{Ac}^{+} / \mathrm{N}^{-} \mathrm{Ac}^{-}\right.$and $\left.\mathrm{N}^{+} \mathrm{Ac}^{+} / \mathrm{N}^{+} \mathrm{Ac}^{-}\right)$. Glu and $\mathrm{Gln}$ were reduced under $\mathrm{N}^{-}$conditions $\left(\mathrm{N}^{-} \mathrm{Ac}^{+} / \mathrm{N}^{+} \mathrm{Ac}^{+}\right.$and $\mathrm{N}^{-} \mathrm{Ac}^{-} / \mathrm{N}^{+} \mathrm{Ac}^{-}$) and increased when acetate was added $\left(\mathrm{N}^{-} \mathrm{Ac}^{+} / \mathrm{N}^{-} \mathrm{Ac}^{-}\right.$and $\left.\mathrm{N}^{+} \mathrm{Ac}^{+} / \mathrm{N}^{+} A \mathrm{c}^{-}\right)$. Accordingly, alpha ketoglutarate acid (AKG), the product of deamidization of $\mathrm{Glu}$, increased under $\mathrm{N}^{-}$conditions $\left(\mathrm{N}^{-} \mathrm{Ac}^{+} / \mathrm{N}^{+} \mathrm{Ac}^{+}\right.$ and $\mathrm{N}^{-} \mathrm{Ac}^{-} / \mathrm{N}^{+} \mathrm{Ac}^{-}$) and was reduced when acetate was added $\left(\mathrm{N}^{-} \mathrm{Ac}^{+} / \mathrm{N}^{-} \mathrm{Ac}^{-}\right.$and $\left.\mathrm{N}^{+} \mathrm{Ac}^{+} / \mathrm{N}^{+} \mathrm{Ac}^{-}\right)$. This was in accord with the previous reports [29]. All amino acids, except Gly and $N$-Isovaleroylglycine, were reduced under $\mathrm{N}^{-}$conditions $\left(\mathrm{N}^{-} \mathrm{Ac}^{+} / \mathrm{N}^{+} \mathrm{Ac}^{+}\right.$and $\left.\mathrm{N}^{-} \mathrm{Ac}^{-} / \mathrm{N}^{+} \mathrm{Ac}{ }^{-}\right)$. Besides, intermediate products of orrnithine-urea cycle, including Asp, fumarate, and orrnithine, were reduced under $\mathrm{N}^{-}$conditions $\left(\mathrm{N}^{-} \mathrm{Ac}^{+} / \mathrm{N}^{+} \mathrm{Ac}^{+}\right.$and $\left.\mathrm{N}^{-} \mathrm{Ac}^{-} / \mathrm{N}^{+} \mathrm{Ac}{ }^{-}\right)$, in accord with the previous reports [30].

\section{Discussion}

\section{$P$. tricornutum use of organic carbon}

In this study, the growth rates of $P$. tricornutum with 0.02 $\mathrm{M}$ glucose, $0.02 \mathrm{M} \mathrm{GL}$, and $0.02 \mathrm{M}$ glycine were compared to those with $0.174 \mathrm{~g} \cdot \mathrm{L}^{-1} \mathrm{NaHCO}_{3}$ and no additional carbon source. The growth rate of $P$. tricornutum on $0.02 \mathrm{M}$ glucose or $0.02 \mathrm{M}$ glycine was significantly lower $(P<0.01)$ compared to $0.174 \mathrm{~g} \cdot \mathrm{L}^{-1} \mathrm{NaHCO}_{3}$ and even lower compared to no additional carbon source (Figure 1G), but the growth rate of $P$. tricornutum on $0.02 \mathrm{M} \mathrm{GL}$ was higher $(P<0.01)$ compared to $0.174 \mathrm{~g} \cdot \mathrm{L}^{-1} \mathrm{NaHCO}_{3}$ after 10 days of culture (Figure 1A). These results indicated GL can promote the growth of $P$. tricornutum significantly, whereas glucose and glycine might not be utilized by the $P$. tricornutum strain used in this study. The complete genome sequence revealed the $P$. tricornutum (CCMP 2561) genome lacks glucose permease (protein-Npi-phospho-L-histidine- 
Table 3 Positional labeling of Ser and Gly

\begin{tabular}{|c|c|c|c|c|}
\hline & $\mathrm{U}-{ }^{13} \mathrm{C}, \mathrm{N}$ plus & $\mathrm{U}-{ }^{13} \mathrm{C}, \mathrm{N}$ minus & $1,3-{ }^{13} \mathrm{C}, \mathrm{N}$ plus & $1,3-13 C, N$ minus \\
\hline Ser1 & $0.175 \pm 0.016$ & $0.332 \pm 0.006$ & $0.137 \pm 0.012$ & $0.080 \pm 0.010$ \\
\hline Ser2 & $0.182 \pm 0.010$ & $0.313 \pm 0.033$ & $0.261 \pm 0.005$ & $0.341 \pm 0.010$ \\
\hline Ser3 & $0.175 \pm 0.017$ & $0.293 \pm 0.010$ & $0.276 \pm 0.011$ & $0.351 \pm 0.001$ \\
\hline Gly1 & $0.167 \pm 0.011$ & $0.295 \pm 0.025$ & $0.126 \pm 0.010$ & $0.076 \pm 0.003$ \\
\hline Gly2 & $0.169 \pm 0.014$ & $0.292 \pm 0.025$ & $0.254 \pm 0.006$ & $0.362 \pm 0.004$ \\
\hline Average FLs of AA & $0.150 \pm 0.008$ & $0.121 \pm 0.005$ & $0.157 \pm 0.014$ & $0.141 \pm 0.007$ \\
\hline Substance FLs & 0.3 & 0.3 & 0.33 & 0.33 \\
\hline
\end{tabular}

$\mathrm{FL}$, fractional labeling.

sugar Npi-phosphotransferase, EC:2.7.1.69) [19], a class of enzymes that catalyze the phosphorylation of glucose and is important for utilization of extracellular glucose by cells. It is likely that the absence of glucose permease results in the poor glucose utilization ability of P. tricornutum (IOCAS-001). For the slow growth rate on glycine, we proposed the ammonium produced during the metabolism of glycine might be toxic to $P$. tricornutum cells because $P$. tricornutum growing on $\mathrm{NH}_{4} \mathrm{Cl}$ also has a slow growth rate (Additional file 1: Figure S1) in this study. Yet there are reports, including the report of Zheng et al., that the mixotrophic growth rate of $P$. tricornutum on glucose or glycine is significantly higher compared to photoautotrophic conditions and accumulated a greater biomass at the plateau phase [1-3,26]. The inconsistent results about glucose utilization of $P$. tricornutum might be due to the use of different trains and different culture conditions. The strain fully sequenced was the P. tricornutum accession Pt1 8.6 deposited as CCMP2561 in the Provasoli-Guillard National Center for Culture of Marine Phytoplankton. The strain used by Zheng et al. was the P. tricornutum strain CCMP 632 obtained from the Provasoli-Guillard National Center for Marine Algae and Microbiota (NCMA) (East Boothbay, ME). The strain used in our study was screened from the East China Sea and maintained in our laboratory for decades and identified as P. tricornutum (IOCAS-001) according to $18 \mathrm{~s}$ ribosomal RNA sequence. Thus, these strains are of different origins. It is probable that these strains are different in genome structure or have mutated (the uptake of a mobile genetic element that carries the genes necessary for glucose utilization or strain mutation over many sub-cultures) and resulted in different glucose utilization abilities. Further, experimental conditions might affect the results. Associated bacteria, for example, might help in the phosphorylation of glucose and thus help in the use of glucose by $P$. tricornutum. The $P$. tricornutum cultures used in this study were purified by growth on agar plates containing multi-antibiotics and shown to be bacteria-free by RT-PCR and sequencing (data not shown) using primers described previously [31,32]. It is likely the absence of associated bacteria explains why $P$. tricornutum has poor ability to use glucose or glycine.

\section{GL metabolism in P. tricornutum}

Our results showed the growth rate under heterotrophic conditions was much lower compared to mixotrophic conditions (Figure 1C,I), indicating light was important for GL metabolism in P. tricornutum.

In vivo, GL can be phosphorylated and converted into dihydroxyacetone phosphate (DHAP) and glyceraldehyde 3-phosphate (GAP) through the following steps:

1. ATP + glycerol $\rightarrow$ ADP + sn-glycerol 3-phosphate

2. sn-glycerol-3-phosphate $+\mathrm{NAD}^{+} \rightarrow \mathrm{DHAP}+$ $\mathrm{NADH}+\mathrm{H}^{+}$

3. DHAP $\rightarrow$ GAP

4. GAP $\rightarrow$ 3-P-glycerate (3PG)

and, finally, DHAP and 3PG can be metabolized through the glucolysis pathway. The complete genome sequence revealed P. tricornutum (CCMP 2561) contains all the enzymes required for the reactions mentioned above, that is, (1) glycerol kinase [gi: 7203857], (2) glycerol-3-phosphate dehydrogenase [gi: 7205122], (3) triosephosphate isomerase [gi: 7202457], and (4) glyceraldehyde-3-phosphate dehydrogenase [gi: 7203381] and phosphoglycerate kinase [gi: 7195255] [19], indicating P. tricornutum (CCMP 2561) can use GL as a carbon source.

The average FL value of protein amino acids was approximately 0.150 for the $30 \%\left(\mathrm{U}_{-}{ }^{13} \mathrm{C}\right)$ labeling experiment (Table 1), indicating nearly half of the carbon came from $\mathrm{CO}_{2}$ fixation and inocula biomass. This suggested GL was assimilated simultaneously with $\mathrm{CO}_{2}$ fixation under mixotrophic conditions, which was likely why $P$. tricornutum under mixotrophic conditions had a higher growth rate compared to heterotrophic conditions. Nevertheless, since at least half of the carbon came from GL, the growth rate under heterotrophic conditions should be approximately half compared to mixotrophic conditions if the GL assimilated was independent of $\mathrm{CO}_{2}$ fixation and light. This was not the case, as suggested by Figure 1C,I, indicating light influences the assimilation of GL. Following the steps described above, metabolism of GL needs large amounts of ATP, which can be generated through photophosphorylation. Besides, DHAP and GAP generated from GL 
Table 4 Ratios of abundances of key cellular metabolites under different culture conditions determined by NMR

\begin{tabular}{|c|c|c|c|c|c|}
\hline Group & Metabolite & $\mathrm{N}-\mathrm{AC}+/ \mathrm{N}-\mathrm{AC}-$ & $\mathrm{N}-\mathrm{AC}+/ \mathrm{N}+\mathrm{AC}+$ & $\mathrm{N}+\mathrm{AC}+/ \mathrm{N}+\mathrm{AC}$ & $\mathrm{N}-\mathrm{AC}-/ \mathrm{N}+\mathrm{AC}-$ \\
\hline \multirow[t]{2}{*}{ Alcohols } & Ethanol & $1.049^{*}$ & $1.067^{*}$ & 1.063 & 1.081 \\
\hline & Ethylene glycol & 0.878 & $2.005^{*}$ & $1.293^{*}$ & $2.952^{* *}$ \\
\hline \multirow[t]{3}{*}{ Amines } & Dimethylamine & $1.153^{*}$ & 1.032 & $1.252^{*}$ & $1.120^{*}$ \\
\hline & Methylamine & $1.143^{*}$ & 1.048 & $0.730^{* *}$ & $0.670^{* *}$ \\
\hline & Trimethylamine & $0.804^{*}$ & $0.573^{* *}$ & 1.140 & $0.812^{*}$ \\
\hline \multirow[t]{19}{*}{ Amino acids } & Alanine & $1.176^{* *}$ & $0.045^{* *}$ & 0.965 & $0.037^{* *}$ \\
\hline & Asparagine & - & $0.000^{* *}$ & $0.569^{* *}$ & $0.000^{* *}$ \\
\hline & Aspartate & - & $0.000^{* *}$ & $1.236^{* *}$ & $0.000^{* *}$ \\
\hline & Betaine & $0.485^{* *}$ & $0.385^{* *}$ & $0.768^{* *}$ & $0.608^{* *}$ \\
\hline & Carnitine & $1.079^{*}$ & 0.931 & 0.997 & $0.860^{*}$ \\
\hline & Glutamate & $1.147^{*}$ & $0.257^{* *}$ & 1.069 & $0.240^{* *}$ \\
\hline & Glutamine & - & $0.000^{* *}$ & $1.220^{* *}$ & $0.000^{* *}$ \\
\hline & Glycine & 0.657 & $1.241^{*}$ & 0.956 & $1.805^{*}$ \\
\hline & Isoleucine & 0.964 & $0.168^{* *}$ & 1.108 & $0.193^{* *}$ \\
\hline & Leucine & $0.876^{* *}$ & $0.278^{* *}$ & 0.880 & $0.279^{* *}$ \\
\hline & Methionine & $1.278^{*}$ & $0.067^{* *}$ & 1.067 & $0.056^{* *}$ \\
\hline & $\mathrm{N}$-Isovaleroylglycine & $1.333^{* *}$ & $2.952^{* *}$ & $1.448^{*}$ & $3.207^{* *}$ \\
\hline & O-Acetylcarnitine & $0.871^{* *}$ & 0.853 & 1.107 & $1.083^{*}$ \\
\hline & Ornithine & - & $0.000^{* *}$ & 0.993 & $0.000^{* *}$ \\
\hline & Phenylalanine & $0.882^{*}$ & $0.462^{* *}$ & 1.073 & $0.561^{* *}$ \\
\hline & Proline & - & $0.000^{* *}$ & 1.177 & $0.000^{* *}$ \\
\hline & Threonine & - & $0.000^{* *}$ & $1.516^{* *}$ & $0.000^{* *}$ \\
\hline & Tyrosine & 0.959 & $0.678^{* *}$ & 1.040 & $0.735^{* *}$ \\
\hline & Valine & $1.283^{* *}$ & $0.154^{* *}$ & 1.001 & $0.120^{* *}$ \\
\hline \multirow[t]{2}{*}{ Amino acid derivatives } & Creatine & $1.296^{* *}$ & $1.658^{* *}$ & $1.192^{* *}$ & $1.526^{* *}$ \\
\hline & Guanidoacetate & $1.198^{*}$ & $0.330^{* *}$ & 0.833 & $0.229^{* *}$ \\
\hline \multirow[t]{3}{*}{ Ammoniums Compounds } & Choline & $0.849^{*}$ & $0.028^{* *}$ & $2.379^{* *}$ & $0.080^{* *}$ \\
\hline & O-Phosphocholine & $0.790^{* *}$ & $1.985^{* *}$ & $0.712^{* *}$ & $1.789^{* *}$ \\
\hline & sn-Glycero-3-phosphocholine & 0.945 & 1.180 & 0.975 & 1.218 \\
\hline Ketones & Acetone & $0.578^{* *}$ & $1.381^{* *}$ & 0.647 & $1.547^{*}$ \\
\hline Methanol & Methanol & 0.944 & 1.052 & 1.023 & $1.142^{*}$ \\
\hline \multirow[t]{2}{*}{ Nucleic acid components } & ATP & $0.000^{* *}$ & $0.000^{* *}$ & 0.797 & $0.335^{* *}$ \\
\hline & $\mathrm{NAD}+$ & 1.002 & $-* *$ & 0.000 & 0.960 \\
\hline \multirow[t]{9}{*}{ Organic acids } & 2-Oxoglutarate & 0.874 & $22.509^{* *}$ & 0.849 & $21.861^{* *}$ \\
\hline & Acetate & $1.077^{*}$ & $1.355^{*}$ & 1.079 & $1.357^{* *}$ \\
\hline & Ascorbate & $0.587^{* *}$ & $0.327^{* *}$ & $1.465^{*}$ & 0.817 \\
\hline & Formate & $0.654^{* *}$ & $1.099^{*}$ & 0.901 & $1.515^{* *}$ \\
\hline & Fumarate & $0.778^{* *}$ & $0.462^{* *}$ & 1.161 & $0.690^{*}$ \\
\hline & Isocitrate & - & - & $0.000^{* *}$ & $0.000^{* *}$ \\
\hline & Lactate & $0.586^{* *}$ & $6.185^{* *}$ & $2.303^{* *}$ & $24.313^{* *}$ \\
\hline & Pyruvate & 0.938 & $0.455^{* *}$ & 1.414 & $0.685^{* *}$ \\
\hline & Succinate & $0.694^{* *}$ & $0.514^{* *}$ & 0.991 & $0.734^{* *}$ \\
\hline
\end{tabular}


Table 4 Ratios of abundances of key cellular metabolites under different culture conditions determined by NMR (Continued)

\begin{tabular}{llllll}
\hline Sugars & Glucose & 1.203 & $1.303^{*}$ & $1.341^{* *}$ & $1.453^{* *}$ \\
& Glucose-1-phosphate & 0.916 & $-^{* *}$ & $-1.200^{* *}$ & - $^{* *}$ \\
& Glucose-6-phosphate & $1.210^{*}$ & $2.031^{* *}$ & 1.022 & $0.739^{* *}$ \\
Glycerol & $0.823^{* *}$ & $0.595^{* *}$ & $0.859^{* *}$ & 1.122 & 0.878 \\
Others & Trigonelline & $1.098^{*}$ & &
\end{tabular}

**Student $t$ test $P$ value $<0.01$, *Student $t$ test $P$ value $<0.05$, ${ }^{-}$Divide by zero.

metabolism were intermediate metabolites of the Calvin cycle. It was likely that consumption of these metabolites through the Calvin cycle promotes GL metabolism in P. tricornutum. We focused on Ser, which had an unexpectedly low level of ${ }^{13} \mathrm{C}$ enrichment at position 1 and was reported to be synthesized via the GOC cycle followed by photorespiratory reactions [26], to investigate other likely pathways for GL metabolism in P. tricornutum.
As was reported, Ser can be synthesized directly from 3PG through a phosphorylated route [33] or from glycine by the glycolate pathway [34]. In P. tricornutum, Ser could be synthesized from GL by four routes (Figure 4): (1) Ser was synthesized directly from GL-derived 3PG through a phosphorylated route, in which case the carbon backbone in GL was not disrupted and Ser should have the same MDV as GL. (2) Ser was synthesized

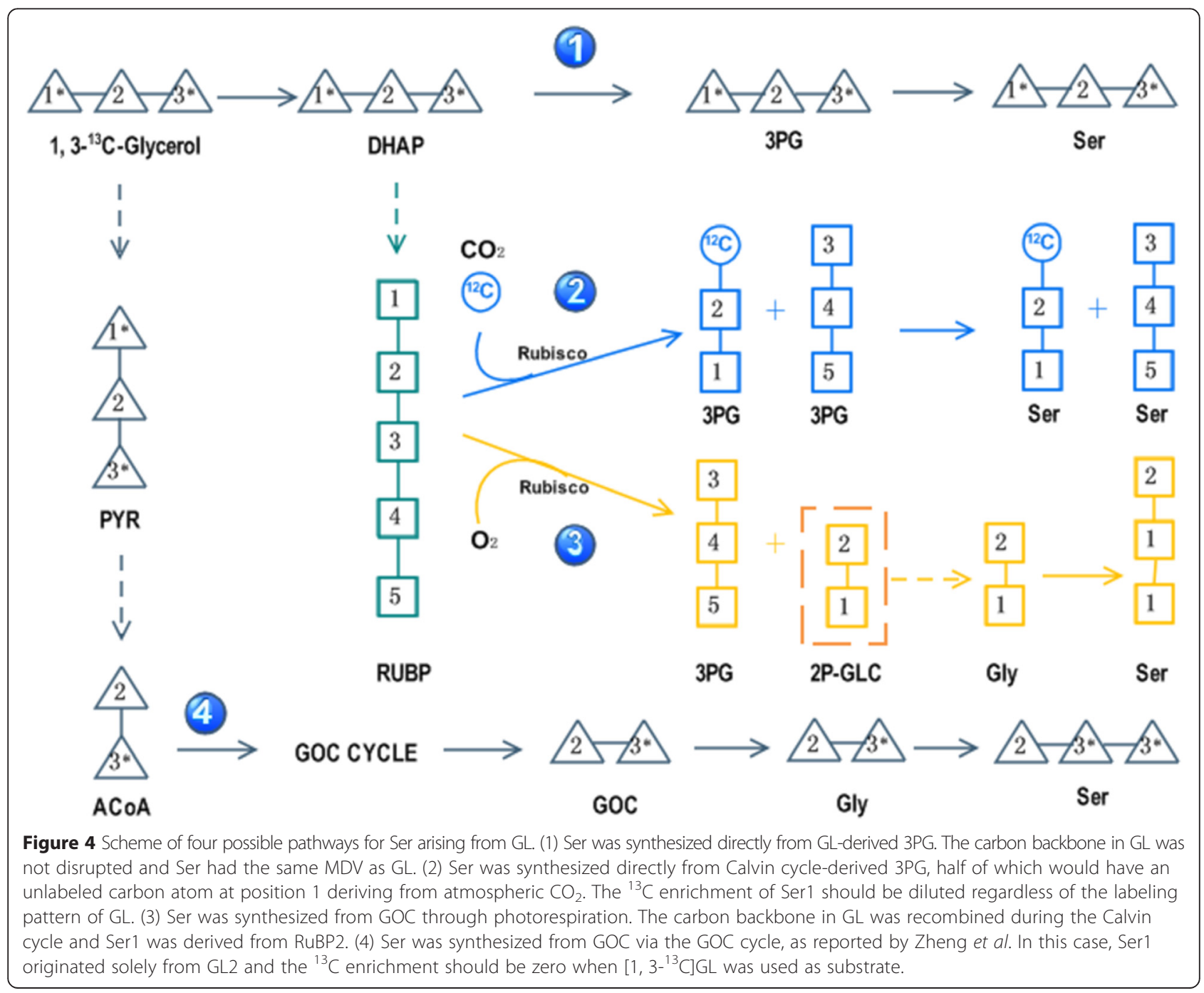


directly from the Calvin cycle-derived 3PG, half of which would have an unlabeled carbon atom derived from atmospheric $\mathrm{CO}_{2}$ in position 1 . In this case, the ${ }^{13} \mathrm{C}$ enrichment of Ser1 should be diluted by half regardless of the labeling pattern of GL. (3) Ser was synthesized from GOC through photorespiration (oxygenation of ribulose1,5-bisphosphate, RuBP). (4) Ser was synthesized from GOC via the GOC cycle, as reported by Zheng et al. [26]; in this case, Ser1 origin solely from GL2, whose ${ }^{13} \mathrm{C}$ enrichment should be zero using $\left[1,3-{ }^{13} \mathrm{C}\right] \mathrm{GL}$ as substrate. Our results showed the ${ }^{13} \mathrm{C}$ enrichment of Ser1 was significantly lower (ca. half under normal condition and much lower under nitrogen-limited condition) compared to Ser2 and Ser3 when $\left[1,3-{ }^{13} \mathrm{C}\right] \mathrm{GL}$ was used as substrate and so was the ${ }^{13} \mathrm{C}$ enrichment of Gly1 relative to Gly2 (Table 3). Nevertheless, both Ser and Gly had similar ${ }^{13} \mathrm{C}$ enrichment in all positions when $\left[\mathrm{U}-{ }^{13} \mathrm{C}\right] \mathrm{GL}$ was used as substrate. Thus, it is unlikely Ser was synthesized solely from route 1 , route 2 or route 4 . It is more likely that Ser was largely synthesized, as in higher plants [34], from Gly via the photorespiratory pathway (route 3 ). In other words, the Calvin cycle and photorespiration took part in GL metabolism in $P$. tricornutum.

\section{The likely response of photorespiration to nitrogen limitation}

It was reported that photorespiration was important for nitrogen assimilation [35]. To investigate the probable relationship between photorespiration and nitrogen assimilation in $P$. tricornutum, we labeled $P$. tricornutum in the absence of nitrogen using $\left[\mathrm{U}_{-}{ }^{13} \mathrm{C}\right] \mathrm{GL}$ or $\left[1,3-{ }^{13} \mathrm{C}\right] \mathrm{GL}$ as substrate. As Table 1 shows, the ${ }^{13} \mathrm{C}$ enrichment of Ser and Gly were increased significantly when those of other amino acids decreased in the absence of nitrogen, regardless of the type of substrate. Synthesis of protein was reduced under nitrogen-limited conditions [36], meaning the de novo synthesis of amino acids would be reduced also. Thus, it was anticipated the ${ }^{13} \mathrm{C}$ enrichment of most amino acids would be reduced. The high FL values of Ser and Gly under nitrogen-limited conditions suggested most Ser and Gly were synthesized de novo using carbon backbones obtained through GL metabolism. As mentioned above, Ser and Gly were synthesized through photorespiration (Figure 4, route 3); thus, the increase of Ser and Gly synthesis indicated the increase of photorespiration under nitrogen-limited conditions, consistent with the suggestion that photorespiration was important for nitrogen assimilation [35]. In addition, the response of diatom to nitrogen limitation was different from that of higher plants and green algae. Instead of photosynthesis, the breakdown of intracellular stores responded for carbon backbone demand for reassimilation of nitrogen [36]. We proposed that photorespiration might be important for redistribution of nitrogen under nitrogen-limited condition.

\section{Influence of sodium acetate on growth of $P$. tricornutum with or without nitrogen}

It was reported photorespiration bypass can improve photosynthesis rates and biomass production in Arabidopsis thaliana $[37,38]$. One bypass was suggested by converting one molecule of GOC with one molecule of acetyl coenzyme A (ACoA) into malate by malate synthase [37-39]. Malate can be metabolized through other pathway (TCA cycle, GOC cycle, and so on) and thus reduce carbon loss through the photorespiratory pathway. To investigate likely photorespiration bypass and its influence on the growth of $P$. tricornutum, we compared the growth of $P$. tricornutum with or without sodium acetate, which can be converted into ACoA by ACoA synthase. The results indicated sodium acetate promoted the growth of $P$. tricornutum in the presence of nitrogen, but growth was decreased in the absence of nitrogen. We proposed that when sodium acetate was added, ACoA was synthesized by ACoA synthase. Excess ACoA promoted the condensation reaction between ACoA and GOC and resulted in the photorespiration bypass in P. tricornutum, which improved biomass production in the present of nitrogen. When nitrogen was limited, $P$. tricornutum had a slower growth rate in the presence of sodium acetate, suggesting photorespiration was important for the nitrogen-limited response in $P$. tricornutum, consistent with reports that photorespiration was important for nitrogen assimilation [35]. Together with the report that genes encoding GOC cycle-related enzymes were down-regulated significantly under nitrogen deprivation [40], we proposed down-regulation of the GOC cycle allows more GOC catalysis through photorespiration. The enhancement of photorespiration might facilitate the redistribution of nitrogen and thus helped $P$. tricornutum to survive under nitrogen-limited conditions. These results also provided evidences for GL metabolism through route 3 but not route 4 (Figure 4). In route 3 , GOC was generated from oxygenation of RuBP. Excess ACoA would transfer GOC into malate, thus reduced carbon loss through following photorespiratory reactions, which would benefit growth under nitrogen-replete conditions but be unfavorable under nitrogen-limited conditions. While in route 4 , glycerol was converted into ACoA and then GOC through the GOC cycle. GOC was metabolized through photorespiratory reactions. Excess ACoA would enhance route 4 (photorespiratory reactions), which should be favorable for growth under nitrogen-limited condition. This was not the case in our results; thus, we suggested that glycerol was largely metabolized through route 3 (Figure 4) in the strain used in this study. 


\section{Metabolic analysis provided further evidences for the importance of photorespiration in nitrogen-limited response}

To obtain further insight into the importance of photorespiration in nitrogen-limited response, the composition of the intracellular metabolite pool under different culture conditions $\left(\mathrm{N}^{-} \mathrm{Ac}^{+}, \mathrm{N}^{-} \mathrm{Ac}^{-}, \mathrm{N}^{+} \mathrm{Ac}^{+}\right.$, and $\left.\mathrm{N}^{+} \mathrm{Ac}^{-}\right)$was measured by NMR and the ratios of abundances of key cellular metabolites were calculated (Table 4). Gly increased under $\mathrm{N}^{-}$conditions $\left(\mathrm{N}^{-} \mathrm{Ac}^{+} / \mathrm{N}^{+} \mathrm{Ac}^{+}\right.$and $\left.\mathrm{N}^{-} \mathrm{Ac}^{-} / \mathrm{N}^{+} \mathrm{Ac}{ }^{-}\right)$and was reduced when acetate was added $\left(\mathrm{N}^{-} \mathrm{Ac}^{+} / \mathrm{N}^{-} \mathrm{Ac}^{-}\right.$and $\mathrm{N}^{+} \mathrm{Ac}^{+} / \mathrm{N}^{+} \mathrm{Ac}^{-}$). In addition, ethylene glycol and formate, which can be produced from intermediate metabolites of photorespiration $\quad$ (glycolate $\rightarrow$ glycolaldehyde $\rightarrow$ ethylene glycol and glyoxylate $\rightarrow$ oxalate $\rightarrow$ formate), had the same expression pattern as Gly (Table 4). These results supported our hypotheses that photorespiration was upregulated under $\mathrm{N}^{-}$condition, whereas addition of acetate would result in photorespiration bypass and suppress the following steps of photorespiration. Besides, Glu and Gln, which participated in photorespiration as nitrogen carriers, were reduced under $\mathrm{N}^{-}$conditions $\left(\mathrm{N}^{-} \mathrm{Ac}^{+} / \mathrm{N}^{+} \mathrm{Ac}^{+}\right.$ and $\mathrm{N}^{-} \mathrm{Ac}^{-} / \mathrm{N}^{+} \mathrm{Ac}^{-}$) and increased when acetate was added $\left(\mathrm{N}^{-} \mathrm{Ac}^{+} / \mathrm{N}^{-} \mathrm{Ac}^{-}\right.$and $\left.\mathrm{N}^{+} \mathrm{Ac}^{+} / \mathrm{N}^{+} \mathrm{Ac}{ }^{-}\right)$. Accordingly, AKG (the precursor of Glu) increased under $\mathrm{N}^{-}$conditions $\left(\mathrm{N}^{-} \mathrm{Ac}^{+} / \mathrm{N}^{+} \mathrm{Ac}^{+}\right.$and $\left.\mathrm{N}^{-} \mathrm{Ac}^{-} / \mathrm{N}^{+} \mathrm{Ac}^{-}\right)$and was reduced when acetate was added $\left(\mathrm{N}^{-} \mathrm{Ac}^{+} / \mathrm{N}^{-} \mathrm{Ac}^{-}\right.$and $\left.\mathrm{N}^{+} \mathrm{Ac}^{+} / \mathrm{N}^{+} \mathrm{Ac} \mathrm{c}^{-}\right)$. In theory, Glu and Gln might have the same expression pattern as Gly (increased under $\mathrm{N}^{-}$conditions). Yet Glu and Gln also played as nitrogen carriers for biosynthesis. Since cell growth and most amino acids were reduced under nitrogen-limited condition (Figure 1D and Table 4), it was probable that an approximately 0.25 -fold amount of Glu was sufficient to support photorespiration.

\section{Likely GL metabolism pathway in P. tricornutum}

Notably, the FL values of Ser and Gly in the absence of nitrogen based on $\left[\mathrm{U}_{-}{ }^{13} \mathrm{C}\right] \mathrm{GL}$ were approximately 0.3 , close to the level of substrate. During photorespiration, $2 \mathrm{P}$-glycolate is generated from oxygenation of RuBP, whose ${ }^{13} \mathrm{C}$ enrichment was inevitably diluted by $\mathrm{CO}_{2}$ during the Calvin cycle. Since Ser and Gly were synthesized from GOC, which was generated from 2P-glycolate, why were they not diluted by $\mathrm{CO}_{2}$ ? Obviously, only when the carbon atoms in position 1 and position 2 of pentose-5phosphate (P5P1 and P5P2) were derived solely from GL could GOC retain a high level of ${ }^{13} \mathrm{C}$ enrichment. This cannot be the case when GL entered the Calvin cycle as GAP, as GAP can also be derived from carboxylation of RuBP whose ${ }^{13} \mathrm{C}$ enrichment would be diluted. Thus, GL likely entered the Calvin cycle in another form, for example, DHAP. Supposing all DHAP was generated from GL (Figure 5), RuBP regeneration started with the condensation reaction of one molecule of GAP and one molecule of
DHAP, generating one molecule of fructoce-6-P (F6P) with GL3_1-generated carbon atoms at F6P1_3. Next, F6P1_2 was transferred to a second molecule of GAP, generating one molecule of xylulose-5-P (X5P) with the GL 3_2-generated carbon backbone at X5P1_2 and one molecule of erythrose-4-P (E4P) with a GL1-derived carbon atom distributed at E4P1. Next, E4P was condensed with a second molecule of DHAP, generating one molecule of sedoheptulose-7-P (S7P) with a GL1derived carbon atom distributed at S7P4 and the GL3_1-derived carbon backbone distributed at S7P1_3. Sequentially, S7P1_2 was transferred to a third molecule of GAP, generating one molecule of X5P with a GL3_2generated carbon backbone distributed at X5P1_2 and one molecule of ribose-5-P (R5P) with GL1-derived carbon atoms distributed at R5P1 and R5P2. Both R5P and $\mathrm{X} 5 \mathrm{P}$ can be converted into ribulose-5-P (Ru5P), which can finally be converted into RuBP. By oxygenation by Rubisco and metabolism through photorespiration, these RuBPs can generate three molecules of Gly: one had carbon atoms generated from GL1 at both positions and the other two had GL2 at Gly1 and GL3 at Gly2. Generated from these Gly, Ser would have a GL1 or GL2-derived carbon atom at Ser1 and GL1 or GL3 at Ser2 and Ser3. In this pathway, Ser and Gly would have a low level of ${ }^{13} \mathrm{C}$ enrichment at position 1 and similar high level of ${ }^{13} \mathrm{C}$ enrichment at other positions. As GL1-derived Ser1 and Gly1 are basically derived from $\mathrm{R} 5 \mathrm{P}$, the ${ }^{13} \mathrm{C}$ enrichment of Gly1 and Ser1 would depend on the ratio of R5P to X5P used in the generation of RuBP. When more R5P is used, a higher ${ }^{13} \mathrm{C}$ enrichment at Gly1 and Ser1 would occur. This might account for the different ${ }^{13} \mathrm{C}$ enrichment in Gly1 and Ser1 under different nitrogen conditions, providing further evidence for GL metabolism through route 3. Ser1 and Gly1 were significantly lower under nitrogenlimited conditions compared to when ample nitrogen was present, indicating the proportion of RuBP generated from R5P decreased. It was probable that R5P was used for synthesis of other compounds, for example, mRNA. $P$. tricornutum might reserve mRNA synthesis under nitrogen-limited conditions to prepare for recovery under optimized conditions, consistent with our results for transcriptome and proteome of P. tricornutum under nitrogen-limited conditions (unpublished data).

\section{Conclusion}

Our results indicated the strain used in this study (IOCAS-001) was different from that in the study of Zheng et al. [26]. Strains that lack a glucose-utilizing ability have a different mechanism for organic carbon metabolism from strains that can use glucose. Photorespiration is involved in GL metabolism and is important for the nitrogen-limited response in P. tricornutum. 


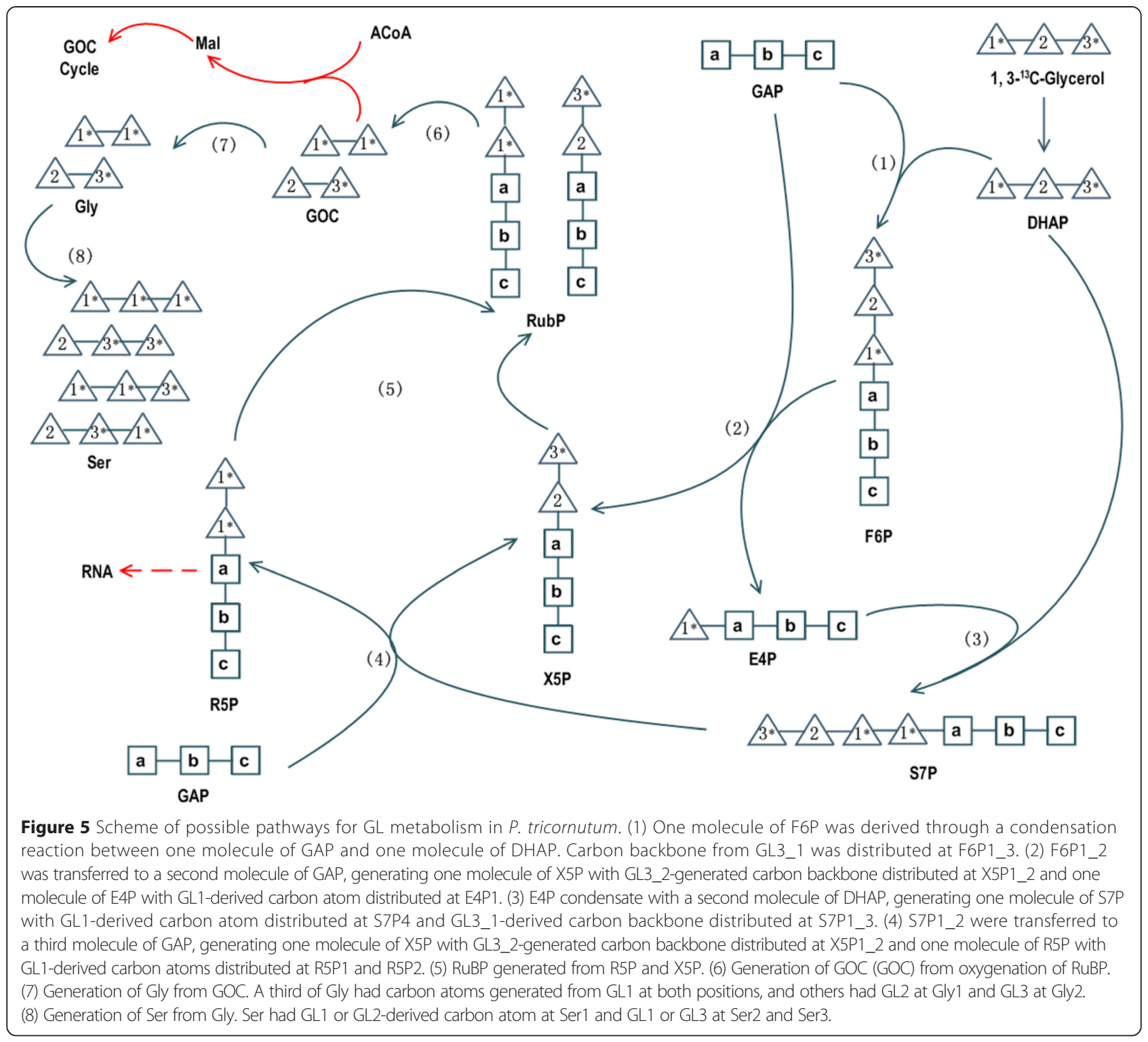

\section{Materials and methods}

\section{Strains and culture conditions}

Axenic cultures of $P$. tricornutum were screened from the East China Sea and maintained in our laboratory for decades and identified as P. tricornutum (IOCAS-001) according to morphological observation and the 18s ribosomal RNA sequence. The cultures were grown in $\mathrm{f} / 2$ medium [41] made with steam-sterilized $\mathrm{NaHCO}_{3}$-free artificial seawater [42] supplemented with $\mathrm{f} / 2$ inorganic nutrients, trace elements and vitamins (sterilized by filtration). One volume of cells in mid-exponential growth phase was harvested by centrifugation for $10 \mathrm{~min}$ at $5000 \times \mathrm{g}$, washed with sterilized $\mathrm{NaHCO}_{3}$-free artificial seawater, and inoculated into nine volumes of fresh medium. Then, $100 \mathrm{mg} \cdot \mathrm{L}^{-1}$ each of ampicillin, kanamycin, and streptomycin were added to avoid bacterial contamination. $\mathrm{NaHCO}_{3}\left(0.174 \mathrm{~g} \cdot \mathrm{L}^{-1}\right)$ or a source of organic carbon (see below) was added. For nitrogen-free experiments, sodium nitrate was omitted from $\mathrm{f} / 2$ inorganic nutrients. For experiments testing the influence of sodium acetate, it was added to a final concentration of $1 \mathrm{~g} \cdot \mathrm{L}^{-1}$. To further test the influence of sodium acetate concentration, it was added to final concentrations of $0,0.1$, $0.5,1$, and $5 \mathrm{~g} \cdot \mathrm{L}^{-1}$, respectively. Each treatment was conducted in triplicate. Cultures were grown at $20^{\circ} \mathrm{C}$ under cool white fluorescent lights at approximately $100 \mu \mathrm{mol} \mathrm{m}{ }^{-2} \cdot \mathrm{s}^{-1}$ with a $12 \mathrm{~h}$ dark $/ 12 \mathrm{~h}$ light cycle for mixotrophic conditions and completely dark for heterotrophic conditions. Cell growth was monitored by measurement of absorbance at $730 \mathrm{~nm}\left(A_{730 \mathrm{~nm}}\right)$ using a UV/visible 
spectrophotometer (Uv-1800; Shimadzu Scientific Instruments, Japan). Cell number was counted using a haemacytometer, and their relationship with the value of $A_{730 n m}$ was determined.

\section{Selection of carbon source and optimization of GL concentration}

Cells were cultured with $0.02 \mathrm{M} \mathrm{GL}$, glucose, or glycine as carbon source. To determine the optimal concentration of GL, cells were cultured with $0.005,0.02$, and $0.1 \mathrm{M} \mathrm{GL}$ as carbon source. $A_{730 \mathrm{~nm}}$ was measured and compared to growth with no additional carbon source and with $\mathrm{NaHCO}_{3}$ at a final concentration of $0.174 \mathrm{~g} \cdot \mathrm{L}^{-1}$ as carbon source.

\section{Determination of GL and acetate concentrations}

The culture was centrifuged at $8,000 \times g$ for $10 \mathrm{~min}$ at room temperature. The supernatant was used to detect extracellular metabolites by LC as described previously [43]. Basically, $10 \mu \mathrm{L}$ sample were loaded onto a Bio-Rad HPX-87H column (Bio-Rad; Hercules, CA, USA) connected to an HPLC system (Agilent 1200) (GMI; Ramsey, $\mathrm{MN}$, USA), eluted with $5 \mathrm{mM} \mathrm{H}_{2} \mathrm{SO}_{4}$ at a flow rate of 0.5 $\mathrm{mL} \cdot \mathrm{min}^{-1}$, and then detected with a differential refraction detector.

\section{Total lipid analysis}

Cells were harvested and quickly froze in liquid nitrogen and then freeze-dried. Total lipids were extracted as described by Bligh and Dyer [44] with minor modifications. Briefly, approximately $20 \mathrm{mg}$ dried cells were mixed with $1 \mathrm{~mL}$ of chloroform/methanol (1:1). The mixture was stirred vigorously for $5 \mathrm{~min}$, after which $0.3 \mathrm{~mL}$ of $0.2 \mathrm{M}$ $\mathrm{H}_{3} \mathrm{PO}_{4}$ (containing $1 \mathrm{M} \mathrm{KCl}$ ) was added and mixed. After centrifugation at $5000 \times \mathrm{g}$ for $5 \mathrm{~min}$, the solvent phase was recovered. This process was repeated three times. The solvent phases were combined, washed three times with distilled water, and then evaporated at room temperature under a ventilated fume hood. The total lipid content was obtained by weighing and expressed as percent cell dry weight (\% CDW).

\section{${ }^{13} \mathrm{C}$ labeling experiment}

GL $(0.02 \mathrm{M})$ was used as the ${ }^{13} \mathrm{C}$-labeling substrate. Midexponential growth phase cells (with $0.174 \mathrm{~g} \cdot \mathrm{L}^{-1} \mathrm{NaHCO}_{3}$ or $0.02 \mathrm{M} \mathrm{GL}$ as carbon source) were harvested by centrifugation for $10 \mathrm{~min}$ at $5000 \times g$, washed with sterilized $\mathrm{NaHCO}_{3}$-free artificial seawater, and inoculated into nine volumes of fresh medium containing a 20\%:80\% (or $30 \%: 70 \%) w / w$ mixture of $\left[\mathrm{U}_{-}{ }^{13} \mathrm{C}\right] \mathrm{GL}$ (99\%; Cambridge isotope laboratories)/unlabeled GL or $50 \%: 50 \% \mathrm{w} / \mathrm{w}$ mixture of $\left[1,3-{ }^{13} \mathrm{C}\right] \mathrm{GL}$ (99\%; Cambridge isotope laboratories)/unlabeled GL. For labeling under N-limited conditions, $\mathrm{NaNO}_{3}$ was omitted from the medium. The labeling experiment lasted for 10 days under normal conditions and a week under $\mathrm{N}$-limited conditions when the cells grew to mid-exponential growth phase. Each treatment was conducted in triplicate.

\section{Sample preparation and gas chromatography-mass spectrometry analysis}

Samples for GC-MS analysis were prepared as described previously [27]. After labeling, cells were harvested by centrifugation for $10 \mathrm{~min}$ at $5000 \times g$, washed with distilled water, and placed into $1.5 \mathrm{~mL}$ Eppendorf tubes and centrifuged for $5 \mathrm{~min}$ at $10,000 \times g$. The supernatants were discarded, and cell pellets were hydrolyzed in $6 \mathrm{M} \mathrm{HCl}$ at approximately $110^{\circ} \mathrm{C}$ for $12 \mathrm{~h}$ then dried overnight at approximately $80^{\circ} \mathrm{C}$. Subsequently, each dried sample was dissolved in $100 \mu \mathrm{L}$ of water-free pyridine then derivatized by the addition of $50 \mu \mathrm{L}$ of $N$-tert-butyldimethylsilyl- $N$ methyltrifluoroacetamide (MTBSTFA) and heated at $85^{\circ} \mathrm{C}$ for $60 \mathrm{~min}$. The sample was centrifuged for $5 \mathrm{~min}$ at $10,000 \times g$, and the supernatant was filtered through $0.22-\mu \mathrm{m}$ pore-size filters and then loaded onto a GC-MS apparatus for analysis as previously described [45]. GCMS was performed with an Agilent 6890-5973 GC-MS (Conquer Scientific; San Diego, CA, USA) system equipped with an Agilent HP-5MS column $(30 \mathrm{~m} \times 0.25 \mathrm{~mm} \times 0.25$ $\mu \mathrm{m})$ with helium as the carrier gas. The oven temperature was programmed at $100^{\circ} \mathrm{C}$ for $2 \mathrm{~min}$ then increased to $260^{\circ} \mathrm{C}$ at a rate of $5^{\circ} \mathrm{C} \min ^{-1}$ and kept at $260^{\circ} \mathrm{C}$ for 10 min. The injection volume was $2 \mathrm{~mL}$, and the MS device was operated in scan mode.

\section{GC-MS data processing}

The GC-MS data were processed as previously described [27]. The mass distribution vector (MDV) for each fragment of 13 amino acid residues (Ala, Gly, Val, Asx, Glx, Pro, His, Phe, Tyr, Ser, Thr, Lys, and Met) and GL were assigned according to Eq. (1), where $m_{0}$ is the fractional abundance of molecules with monoisotopic mass and $m_{i>0}$ is the abundance of fragments with greater mass [46] and corrected for the natural abundance of stable isotopes of $\mathrm{O}, \mathrm{N}, \mathrm{Si}, \mathrm{S}, \mathrm{H}$, and $\mathrm{C}$ [27].

$$
M D V_{a}=\left[\begin{array}{c}
\left(m_{0}\right) \\
\left(m_{1}\right) \\
\vdots \\
\left(m_{n}\right)
\end{array}\right] \text { with } \sum_{i=0}^{n} m_{i}=1
$$

The fractional labeling (FL) of each fragment was calculated according to Eq. (2), where $m i$ has the same meaning as Eq. (1) [45]. 


$$
\mathrm{FL}=\frac{\sum_{i=0}^{n} i \cdot m_{i}}{n \cdot \sum_{i=0}^{n} m_{i}}
$$

\section{Metabolite analysis \\ Cells cultured under $\mathrm{N}^{-} \mathrm{Ac}^{+}, \mathrm{N}^{-} \mathrm{Ac}^{-}, \mathrm{N}^{+} \mathrm{Ac}^{+}$, and $\mathrm{N}^{+} \mathrm{Ac}^{-}$ conditions were harvested and quickly frozen in liquid nitrogen, then freeze-dried. Metabolites were extracted and analysis by NMR as described previously [47]. Stu- dent $t$ test was used to detect significance of differences between samples.}

\section{Additional file}

Additional file 1: Figure S1. Growth of $P$. tricornutum on $\mathrm{NH}_{4} \mathrm{Cl}$ and $\mathrm{NaNO}_{3}$ as nitrogen sources.

\section{Abbreviations}

PUFA: polyunsaturated fatty acids; GC-MS: gas chromatography mass spectrometry; NMR: nuclear magnetic resonance; GL: glycerol; CDW: cell dry weight; FL: fractional labeling; PEP: phosphoenolpyruvate; E4P: erythrose-4-P; MDV: mass distribution vector; DHAP: dihydroxyacetone phosphate; GAP: glyceraldehyde 3-phosphate; 3PG: 3-P-glycerate; RuBP: ribulose-1,5bisphosphate; ACoA: acetyl coenzyme A; P5P: pentose-5-phosphate: F6P: fructoce-6-P; X5P: xylulose-5-P; E4P: erythrose-4-P:

S7P: sedoheptulose-7-P; R5P: ribose-5-P; Ru5P: ribulose-5-P; MTBSTFA: $\mathrm{N}$-tert-butyldimethylsilyl-N-methyltrifluoroacetamide.

\section{Competing interests}

The authors declare that they have no competing interests.

\section{Authors' contributions}

AYH carried out the experiments, performed the data analysis, and drafted the manuscript. $L X L$ cultured the $P$. tricornutum, prepared the samples, and participated in data analysis. CY conceived of the study and performed the data analysis. GCW conceived of the study and drafted the manuscript. All authors read and approved the manuscript.

\section{Acknowledgements}

This work was supported by the National Natural Science Foundation of China (41406169), International Science \& Technology Cooperation Program of China (ISTCP, 2015DFG32160), Ministry of Science and Technology of the PRC fundamental research work (NO. 2012FY112900-01), Science and Technology Strategic Pilot of the Chinese Academy of Sciences (XDA05030401), and the General Financial Chinese Grant from the China Postdoctoral Science Foundation (2014 M551970).

\section{Author details}

${ }^{1}$ Institute of Oceanology, Chinese Academy of Sciences, Qingdao 266071, China. ${ }^{2}$ Institute of Plant Physiology and Ecology, Shanghai Institute for Biological Sciences, Chinese Academy of Sciences, Shanghai 200032, China.

Received: 3 February 2015 Accepted: 17 April 2015

\section{Published online: 03 May 2015}

\section{References}

1. Garci MCC, Sevilla JMF, Fernandez FGA, Grima EM, Camacho FG. Mixotrophic growth of Phaeodactylum tricornutum on glycerol: growth rate and fatty acid profile. J Appl Phycol. 2000;12:239-48.

2. Garcia MCC, Miron AS, Sevilla JMF, Grima EM, Camacho FG. Mixotrophic growth of the microalga Phaeodactylum tricornutum - influence of different nitrogen and organic carbon sources on productivity and biomass composition. Process Biochem. 2005;40:297-305.
3. Ceron Garcia MC, Camacho FG, Miron AS, Sevilla JMF, Chisti Y, Grima EM. Mixotrophic production of marine microalga Phaeodactylum tricornutum on various carbon sources. J Microbiol Biotechnol. 2006;16:689-94.

4. Kobayashi M, Kakizono T, Nagai S. Enhanced carotenoid biosynthesis by oxidative stress in acetate-induced cyst cells of a green unicellular alga, Haematococcus pluvialis. Appl Environ Microbiol. 1993;59:867-73.

5. Lee YK, Ding SY, Hoe CH, Low CS. Mixotrophic growth of Chlorella sorokiniana in outdoor enclosed photobioreactor. J Appl Phycol. 1996:8:163-9.

6. Field C, Behrenfeld M, Randerson J, Falkowski P. Primary production of the biosphere: integrating terrestrial and oceanic components. Sci. 1998;281:237-40.

7. Falkowski P, Barber R, Smetacek V. Biogeochemical controls and feedbacks on ocean primary production. Sci. 1998;281:200-6.

8. Demirbas A. Biodiesel: a realistic fuel alternative for diesel engines. London: Springer Verlag; 2008.

9. Francius G, Tesson B, Dague E, Martin-Jezequel V, Dufrene YF. Nanostructure and nanomechanics of live Phaeodactylum tricornutum morphotypes. Environ Microbiol. 2008; 10:1344-56

10. De Martino A, Meichenin A, Shi J, Pan KH, Bowler C. Genetic and phenotypic characterization of Phaeodactylum tricornutum (Bacillariophyceae) accessions. J Phycol. 2007:43:992-1009.

11. Borowitzka M, Volcani B. The polymorphic diatom Phaeodactylum tricornutum: ultrastructure of its morphotypes. J Phycol. 1978;14:10-21.

12. Gutenbrunner S, Thalhamer J, Schid A. Mm (1994) proteinaceaous and immunochemical distinctions between the oval and fusirom morphotypes of Phaeodactylum tricornutum (Bacillariophyceae). J Phycol. 1994:30:129-36.

13. Patil V, Reitan Kl, Knutsen G, Mortensen LM, Källqvist T, Olsen E, et al. Microalgae as source of polyunsaturated fatty acids for aquaculture. Curr Top Plant Biol. 2005;6:57-65.

14. Owens TG, Wold ER. Light-harvesting function in the diatom Phaeodactylum tricornutum I. Isolation and characterization of pigment-protein complexes. Plant Physiol. 1986:80:732-8.

15. Kim JM, Araki S, Kim DJ, Park CB, Takasuka N, Baba-Toriyama H, et al. Chemopreventive effects of carotenoids and curcumins on mouse colon carcinogenesis after 1, 2-dimethylhydrazine initiation. Carcinogenesis. 1998;19:81-5

16. Nomura T, Kikuchi M, Kubodera A, Kawakami Y. Proton-donative antioxidant activity of fucoxanthin with 1, 1-diphenyl-2-picrylhydrazyl (DPPH). IUBMB Life. 1997:42:361-70.

17. Maeda H, Hosokawa M, Sashima T, Funayama K, Miyashita K. Fucoxanthin from edible seaweed, Undaria pinnatifida, shows antiobesity effect through ucp1 expression in white adipose tissues. BBRC. 2005;332:392-7.

18. Matsumoto M, Hosokawa M, Matsukawa N, Hagio M, Shinoki A, Nishimukai $M$, et al. Suppressive effects of the marine carotenoids, fucoxanthin and fucoxanthinol on triglyceride absorption in lymph duct-cannulated rats. Eur J Nutr. 2010:49:243-9.

19. Bowler C, Allen AE, Badger JH, Grimwood J, Jabbari K, Kuo A, et al. The Phaeodactylum genome reveals the evolutionary history of diatom genomes. Nature. 2008:456:239-44.

20. Apt KE, Grossman A, Kroth-Pancic P. Stable nuclear transformation of the diatom Phaeodactylum tricornutum. Mol Gen Genet MGG. 1996;252:572-9.

21. De Risco V, Raniello R, Maumus F, Rogato A, Bowler C, Falciatore A. Gene silencing in the marine diatom Phaeodactylum tricornutum. NAR. 2009:37:e96-6.

22. Siaut M, Heijde M, Mangogna M, Montsant A, Coesel S, Allen A, et al. Molecular toolbox for studying diatom biology in Phaeodactylum tricornutum. Gene. 2007:406:23-35

23. Zaslavskaia L, Lippmeier J, Kroth P, Grossman A, Apt K. Transformation of the diatom Phaeodactylum tricornutum (Bacillariophyceae) with a variety of selectable marker and reporter genes. J Phycol. 2000;36:379-86.

24. Ceron-Garcia MC, Fernandez-Sevilla JM, Sanchez-Miron A, Garcia-Camacho F, Contreras-Gomez A, Molina-Grima E. Mixotrophic growth of Phaeodactylum tricornutum on fructose and glycerol in fed-batch and semi-continuous modes. Bioresour Technol. 2013;147:569-76.

25. Ukeles $\mathrm{R}$, Rose WE. Observations on organic-carbon utilization by photosynthetic marine microalgae. Mar Biol. 1976;37:11-28.

26. Zheng YT, Quinn AH, Sriram G. Experimental evidence and isotopomer analysis of mixotrophic glucose metabolism in the marine diatom Phaeodactylum tricornutum. Microb Cell Fact. 2013;12:16.

27. Nanchen A, Fuhrer T, Sauer U. Determination of metabolic flux ratios from ${ }^{13} \mathrm{C}$-experiments and gas chromatography-mass spectrometry data. Methods Mol Biol. 2007;358:92 
28. Rosman K, Taylor P. Isotopic compositions of the elements 1997. JPCRD. 1998:27:1275.

29. Guerra LT, Levitan O, Frada MJ, Sun JS, Falkowski PG, Dismukes GC. Regulatory branch points affecting protein and lipid biosynthesis in the diatom Phaeodactylum tricornutum. Biomass \& Bioenergy. 2013;59:306-15.

30. Allen AE, Dupont CL, Obornik M, Horak A, Nunes-Nesi A, McCrow JP, et al. Evolution and metabolic significance of the urea cycle in photosynthetic diatoms. Nature. 2011:473:203-9.

31. Edwards U, Rogall T, Blocker H, Emde M, Bottger EC. Isolation and direct complete nucleotide determination of entire genes. Characterization of a gene coding for 16S-ribosomal RNA. NAR. 1989;17:7843-53.

32. Weisburg WG, Barns SM, Pelletier DA, Lane DJ. 16 s ribosomal DNA amplification for phylogenetic study. J Bacteriol. 1991;173:697-703.

33. Colman B, Norman EG. Serine synthesis in cyanobacteria by a nonphotorespiratory pathway. Physiol Plant. 1997;100:133-6.

34. Husic DW, Husic HD, Tolbert NE, Black Jr CC. The oxidative photosynthetic carbon cycle or $C_{2}$ cycle. Crit Rev Plant Sci. 1987:5:45-100.

35. Rachmilevitch $S$, Cousins AB, Bloom AJ. Nitrate assimilation in plant shoots depends on photorespiration. Proc Natl Acad Sci U S A. 2004;101:11506-10.

36. Hockin NL, Mock T, Mulholland F, Kopriva S, Malin G. The response of diatom central carbon metabolism to nitrogen starvation is different from that of green algae and higher plants. Plant Physiol. 2012;158:299-312.

37. Peterhansel C, Blume C, Offermann S. Photorespiratory bypasses: how can they work? JExB. 2013;64:709-15.

38. Maier A, Fahnenstich H, Von Caemmerer S, Engqvist M, Weber A, Flugge U, et al. Glycolate oxidation in A. thaliana chloroplasts improves biomass production. Frontiers in Plant Science. 2012;3:38.

39. Fahnenstich $H$, Scarpeci TE, Valle EM, Flügge U-I, Maurino VG. Generation of hydrogen peroxide in chloroplasts of Arabidopsis overexpressing glycolate oxidase as an inducible system to study oxidative stress. Plant Physiol. 2008;148:719-29.

40. Yang Z-K, Niu Y-F, Ma Y-H, Xue J, Zhang M-H, Yang W-D, et al. Molecular and cellular mechanisms of neutral lipid accumulation in diatom following nitrogen deprivation. Biotechnology for Biofuels. 2013;6:67.

41. Guillard, Robert RL. Culture of phytoplankton for feeding marine invertebrates. In: Smith WL, Chanley MH, editors. Culture of marine invertebrate animals. New York: Plenum Press; 1975. p. 29-60.

42. Harrison P, Waters R, Taylor F. A broad spectrum artificial sea water medium for coastal and open ocean phytoplankton. J Phycol. 1980;16:28-35.

43. Sun L, Huang A, Gu W, Ma Y, Zhu D, Wang G. Hydrogen production by Enterobacter cloacae isolated from sugar refinery sludge. IJHE. 2015;40:1402-7.

44. Bligh EG, Dyer WJ. A rapid method of total lipid extraction and purification Can J Biochem Physiol. 1959;37:911-7.

45. Xiong W, Liu L, Wu C, Yang C, Wu Q. ${ }^{13}$ C-tracer and gas chromatographymass spectrometry analyses reveal metabolic flux distribution in the oleaginous microalga Chlorella protothecoides. Plant Physiol. 2010;154:1001-11.

46. Fischer E, Sauer U. Metabolic flux profiling of Escherichia coli mutants in central carbon metabolism using GC-MS. EJBio. 2003;270:880-91.

47. Ge F, Huang WC, Chen Z, Zhang CY, Xiong Q, Bowler C, et al. Methylcrotonyl-coa carboxylase regulates triacylglycerol accumulation in the model diatom Phaeodactylum tricornutum. Plant Cell. 2014;26:1681-97.

\section{Submit your next manuscript to BioMed Central and take full advantage of:}

- Convenient online submission

- Thorough peer review

- No space constraints or color figure charges

- Immediate publication on acceptance

- Inclusion in PubMed, CAS, Scopus and Google Scholar

- Research which is freely available for redistribution 